Boston University School of Law Scholarly Commons at Boston University School of Law

Faculty Scholarship

2013

\title{
Against Endowment Theory: Experimental Economics and Legal Scholarship
}

Greg Klass

Boston University School of Law

Kathryn Zeiler

Boston University School of Law

Follow this and additional works at: https://scholarship.law.bu.edu/faculty_scholarship

Part of the Behavioral Economics Commons, Economic Theory Commons, and the Law and Economics Commons

\section{Recommended Citation}

Greg Klass \& Kathryn Zeiler, Against Endowment Theory: Experimental Economics and Legal Scholarship, 61 UCLA Law Review 2 (2013).

Available at: https://scholarship.law.bu.edu/faculty_scholarship/199 
2013

\section{Against Endowment Theory: Experimental Economics and Legal Scholarship}

Gregory Klass

Georgetown UniversityLaw Center, gmk9@law.georgetown.edu

Kathryn Zeiler

Georgetown University Law Center, zeiler@law.georgetown.edu

Georgetown Public Law and Legal Theory Research Paper No. 13-013

Georgetown Business, Economics and Regulatory Law Research Paper No. 13-005

This paper can be downloaded free of charge from:

http://scholarship.law.georgetown.edu/facpub/1181

http://ssrn.com/abstract=2224105

61 UCLA L. Rev. 2-64 (2013)

This open-access article is brought to you by the Georgetown Law Library. Posted with permission of the author.

Follow this and additional works at: http://scholarship.law.georgetown.edu/facpub

Part of the Behavioral Economics Commons, Legal Education Commons, Legal Theory Commons, and the Legal Writing and Research 


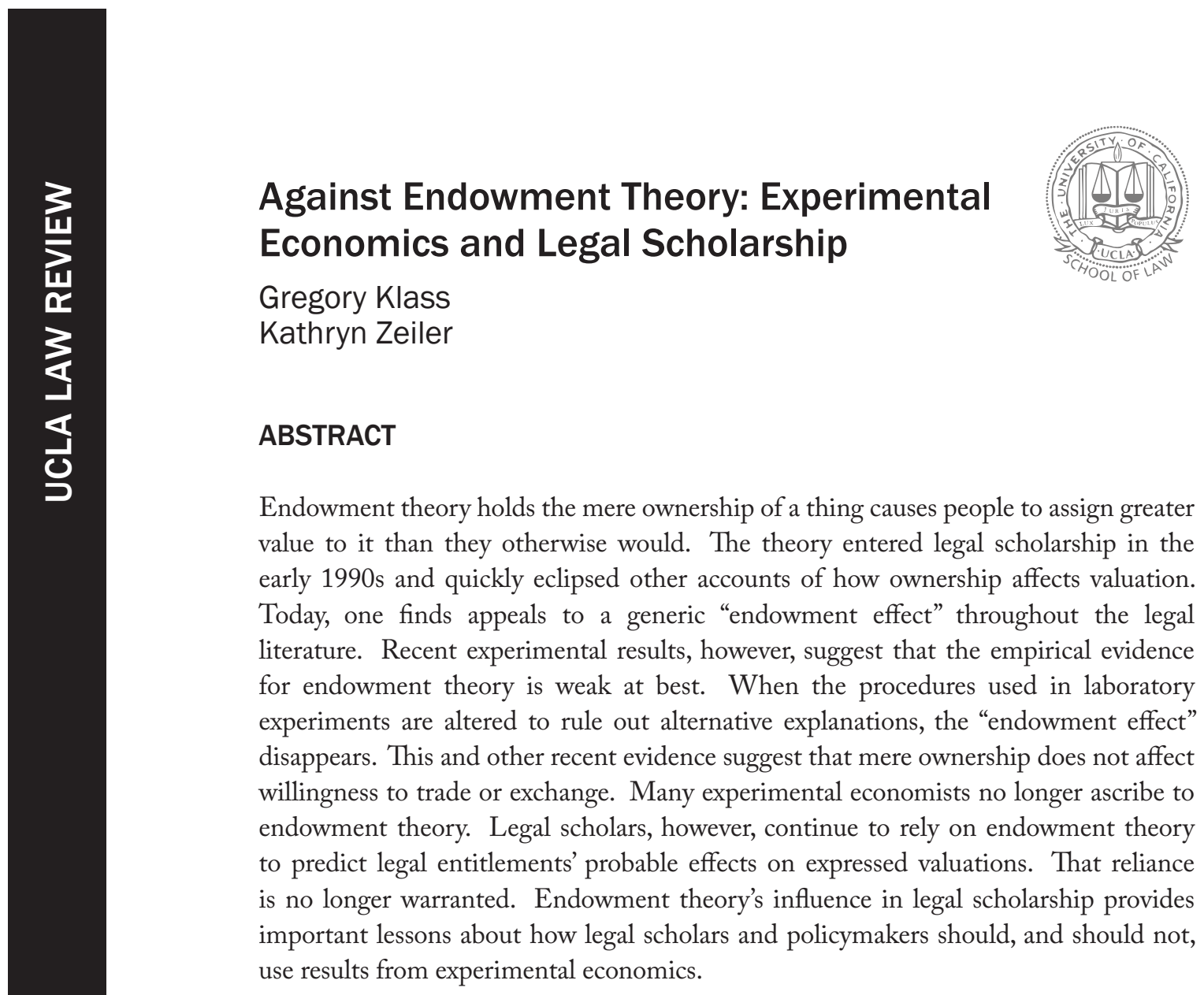

\section{AUTHORS}

Gregory Klass is Professor of Law and Associate Dean of Research and Academic Programs, Georgetown University Law Center. Kathryn Zeiler is Professor of Law, Georgetown University Law Center. Many provided insightful comments on this and earlier drafts, including Robert Ahdieh, Jack Beermann, Gregg Bloche, Richard Craswell, Heidi Li Feldman, Matthew Gerke, James Griener, Vicki Jackson, Donald Langevoort, David Luban, John Mikhail, Alison Morantz, William Park, Eduardo Peñalver, Charles Plott, Jedediah Purdy, Warren Schwartz, Michael Seidman, Matthew Stephenson, Christian Turner, and Robin West. We also received helpful comments from law school workshop participants at Boston University, Cornell University, Emory University, George Mason University, Georgetown University, Harvard University, Hebrew University, HEC Montreal, the University of Bologna, the University of Michigan, the University of North Carolina, the University of Paris, the University of Pennsylvania, Stanford University, and the Federal Trade Commission. We received stellar research assistance from Stacy Goto, Carl Hinneschiedt, Sophia Lee, Louis Rosenberg, and Joseph Shifer.

61 UCLA L. Rev. 2 (2013) 


\section{TABLE OF CONTENTS}

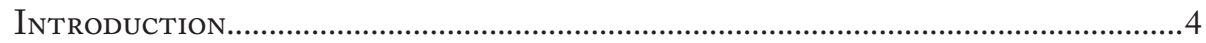

I. Legal Scholarship and Endowment Theory ..............................................

A. Early Critics of Coase: Ownership, Preferences, and Exogeneity ..................9

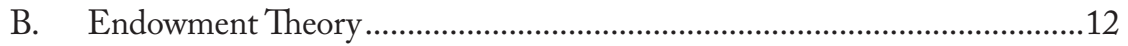

C. Endowment Theory in Legal Scholarship.................................................18

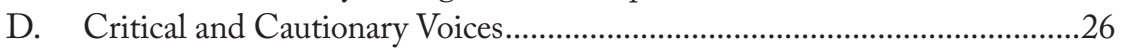

II. Empirical Findings From the Past Decade ...............................................30

A. The Strength of the Original Evidence ..........................................................

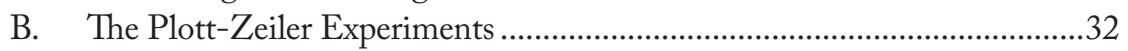

1. Evidence of Subject Misconceptions in Price Experiments................33

2. Evidence of the Influence of Enhancements

in Exchange Experiments.................................................................39

3. Possible Misinterpretations ..................................................................

C. Economics Research After Plott and Zeiler ................................................46

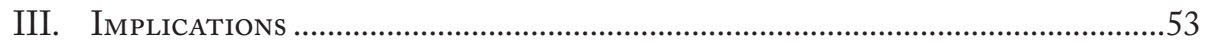

A. Against Endowment Theory: Ownership, Preferences,

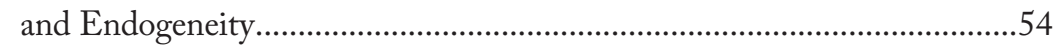

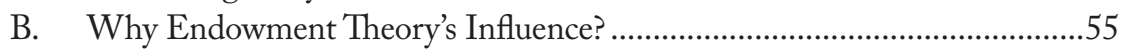

C. Experimental Economics and Legal Scholarship.......................................59

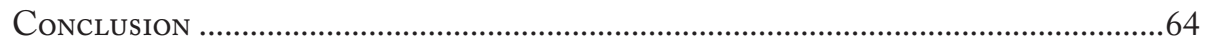




\section{INTRODUCTION}

A popular theory of the endowment effect, or what we will call "endowment theory," says that the simple fact of owning something influences a person's expressed preferences with respect to it. ${ }^{1}$ Our everyday experience might seem to confirm the hypothesis. We feel a special attachment to the house we own, to the car we drive, or even to an old paperback, coffee mug, or well-worn tshirt. A person who would never spend one-hundred dollars on a bottle of wine but receives a one-hundred dollar bottle as a gift will choose to drink the wine rather than sell it. And when in controlled experiments psychologists give subjects pens or mugs or chocolate bars, the recipients tend to hold onto those endowed items rather than trade or sell them.

Endowment theory says that such observable events, whatever their other possible causes, are at least partially explained by the general phenomenon of loss aversion. Prospect theory holds that when deciding what to do, people give possible losses more weight than potential gains of the same magnitude. Endowment theory is an application of prospect theory, adding the hypothesis that ownership determines whether one experiences a change as a gain or as a loss. Endowment theory posits that ownership sets one's reference point, the movement from which triggers either a perceived gain or loss, and that people perceive the transfer or sale of endowments as losses.

If correct, endowment theory does two things. First, it explains why people often appear to value what they own more than they value otherwise identical goods they do not own. Loss aversion reduces an owner's willingness to trade by generating an extra disutility from a loss of a good or right, separate from and in addition to the lost consumption value. Second, the theory licenses a general inference from ownership to reluctance to trade. Endowment theory predicts that, other things being equal, giving a person something will change her expressed preferences with respect to it.

Legal scholars have embraced endowment theory with gusto. Ronald Coase taught us to think of laws as granting entitlements that might in theory be traded. Environmental laws give the factory an entitlement to pollute or they give homeowners an entitlement to clean air; property law gives the farmer an entitlement to grow wheat or the railroad an entitlement to emit sparks; the law of nuisance gives one neighbor an entitlement to quiet enjoyment or the other an

1. Part I.B describes the theory in more detail. See generally Richard Thaler, Torward a Positive Theory of Consumer Choice, 1 J. ECON. BEHAV. \& ORG. 39 (1980); Amos Tversky \& Daniel Kahneman, Loss Aversion in Riskless Choice: A Reference-Dependent Model, 106 Q.J. ECON. 1039 (1991). 
entitlement to make noise. Because entitlements are owned, this Coasian way of thinking has permitted legal scholars to apply endowment theory to everything from the right to contract performance to the right to fair use of copyrighted materials to a criminal defendant's right to a jury trial. ${ }^{2}$

Although endowment theory continues to enjoy considerable influence in the legal literature, recent experimental data have cast doubt on the hypothesis that ownership sets the reference point and loss aversion generates reluctance to trade. The empirical support for endowment theory was never perfect. In recent years, experimentalists have published data suggesting that the results of earlier laboratory experiments were not caused by loss aversion but by other factors. ${ }^{3}$ By making a few changes to the experimental design-like better training subjects in the auction mechanisms used in the experiments, changing the way subjects were given the items, and modifying the procedures for eliciting choices-to rule out alternative explanations, experimentalist were able to make "endowment effects" that had been observed in the laboratory disappear. Many other researchers have since replicated these results. The new data suggest that ownership alone is not enough to change people's expressed preferences. These results have led experimental economists and cognitive psychologists to develop alternatives to endowment theory.

The legal literature has not kept up. Legal scholars today still write as if bare ownership, or "entitlement" or "endowment," were enough to affect individuals' willingness to trade or sell, as if endowment theory were still one of the most robust results of behavioral economics. Having drawn heavily from experimental literature in the early 1990s, many legal scholars have not since returned to the source. Thus while experimentalists have called into question the thesis that the simple fact of ownership predictably changes people's expressed preferences, legal scholars still write as if it does.

The causes of endowment theory's early and continued popularity in the legal literature are themselves complex. Part I tells the story of how endowment theory entered and then spread throughout legal scholarship. Early critics of law and economics suggested many different reasons why ownership might affect

2. See infra notes 84-111. Although these writers are typically making points at odds with the Coase theorem, they remain within the broader Coasian framework. They analyze laws as creating entitlements.

3. See Charles R. Plott \& Kathryn Zeiler, Exchange Asymmetries Incorrectly Interpreted as Evidence of Endowment Effect Theory and Prospect Theory?, 97 AM. ECON. REV. 1449 (2007) [hereinafter Plott \& Zeiler, Exchange Asymmetries]; Charles R. Plott \& Kathryn Zeiler, The Willingness to PayWillingness to Accept Gap, the "Endowment Effect," Subject Misconceptions, and Experimental Procedures for Eliciting Valuations, 95 AM. ECON. REV. 530, 536-38 (2005) [hereinafter Plott \& Zeiler, Willingness to Pay]. 
preferences or willingness to trade. Starting around 1990, one explanation came to dominate: endowment theory. Because endowment theory posits that reluctance to trade or sell is a special instance of the general phenomenon of loss aversion, it predicts that ownership will trigger reluctance to trade across a wide variety of contexts. Over the past two decades, endowment theory has become accepted wisdom among legal scholars, and appeals to the "endowment effect" are now ubiquitous. This Article's first aim is to tell the story of how endowment theory entered into and spread through legal scholarship.

Part II introduces work published in experimental economics in the mid2000s on the effects of ownership on willingness to trade. It is now over twenty years since experimentalists first claimed to observe "endowment effects." In the early 1990s, it was not unreasonable for legal scholars to treat endowment theory as the leading explanation of asymmetries in willingness to trade, though even then the evidence for the theory was mixed, with some supporting alternative explanations. In the years since, experimentalists have raised new doubts about endowment theory. Data produced during the last decade suggest that loss aversion is not the best account for observed reluctance to trade, and that the complete explanation of the phenomena is much more complex. Legal scholars who make claims about the effects of ownership on expressed preferences need to understand the best contemporary theories of the phenomenon. This Article's second goal is to introduce them to that body of work.

Part III draws some general lessons about the use of behavioral economics in legal scholarship. Endowment theory's influence on legal scholarship provides a cautionary tale. It demonstrates the care legal scholars should take when drawing policy lessons from the latest behavioral theory. It shows the dangers of treating early works by leading figures as authoritative, which can result in a mere hypothesis being treated as a truism. And it reveals the risks of legal scholars' tendency to focus on the results of a single experiment rather than on the theory that best explains a pattern of data produced by many different empirical tests. This Article's third purpose is methodological: to venture some recommendations about how legal scholars can best use the science of economics.

In arguing that the best available evidence no longer supports endowment theory, we are neither rejecting behavioral economics writ large nor defending the descriptive adequacy of neoclassical economic models. Our thesis is simply that the inference from ownership, endowment, or entitlement directly to reluctance to trade is no longer warranted. Legal scholars and policymakers should not simply assume that assigning someone an entitlement will change the value she attaches to it. If this is correct, many contemporary claims about the probable effects of legal entitlements require additional support. Such support might 
well be available. To reject endowment theory is not to claim that ownership is never correlated with reluctance to trade or that entitlements do not sometimes affect preferences. But those advancing such claims need to explain why they expect such effects in the case under discussion. They can no longer rely on a generic endowment effect. We close with a note regarding the importance of the explanation for policy prescriptions.

\section{LEGAL SCHOLARSHIP AND ENDOWMENTTHEORY}

Endowment theory has been touted as one of the most robust theories in the field of behavioral economics. This Part tells the story of how the theory gained dominance in legal scholarship, and how legal scholars found in it an endless supply of descriptive and normative lessons about the law. ${ }^{4}$

Before jumping into the analysis, we want to draw some distinctions and clarify the vocabulary we will be using. We use "willingness to trade" as a generic term to describe people's expressed willingness to exchange something they have for something they do not. Those somethings might be goods or money, or they might be more abstract entitlements, such as the right to pollute or the right to clean air. Much of the literature emphasizes two sorts of observable facts about people's willingness to trade. First, the maximum amount a person is willing to pay to acquire a good or other entitlement is often less than the minimum she would be willing to accept to give up an apparently identical good or entitlement. These are known in the literature as "willingness-to-accept/willingness-to-pay gaps," or "WTA-WTP gaps." Second, in situations in which people are endowed with one good and asked whether they want to exchange it for an alternative good of seemingly similar value, they display a reluctance to do so. This phenomenon is known as an "exchange asymmetry." Asymmetric willingness to trade, which describes both WTA-WTP gaps and exchange asymmetries, should not be confused with a person's valuation of a good or entitlement-or her preferences with respect to it. A person might be unwilling to trade a good or entitlement because she values it highly, or she might be unwilling to trade for strategic reasons, because of social expectations, because she is risk averse or loss averse, or for other reasons.

The above points of parlance will be familiar to anyone who knows the behavioral economics literature. More novel is our use of the term "endowment theory" rather than "endowment effect." Endowment theory maintains that

4. For a more general account of the impact of behavioral economics on legal scholarship, see MARK KELMAN, THE HEURISTICS DEBATE 42-48 (2011). 
WTA-WTP gaps and exchange asymmetries are caused by reference-dependent preferences and loss aversion, features of preferences we describe in more detail later in this Part. We think an important factor in the success of endowment theory in the legal literature has been branding. In 1980, when Richard Thaler introduced endowment theory, he named his explanatory hypothesis the "endowment effect." ${ }^{\text {Th }}$ This term invites confusion. It suggests that the link between ownership and valuation is a simple fact about human psychology, one that is directly observable in the laboratory and therefore might also exist outside of the laboratory, in specifically legal contexts. We would guess that many legal scholars who speak of an "endowment effect" do not think of it as a theory, but as an observable phenomenon. ${ }^{6}$ But this is to confuse the explicandum with the explicans, the phenomenon (WTA-WTP gaps and exchange asymmetries) with a proposed explanation of it (reference dependence and loss aversion). ${ }^{7}$ Observed correlations between changes in ownership and changes in willingness to trade do not on their own demonstrate that the bare fact of ownership causes the changes. Nor do they license a prediction that other forms of ownership of other types of things in other sorts of contexts will have a similar effect. For that, we need a theory. Thaler proposed one: loss aversion plus the hypothesis that ownership sets the reference point. This is not an effect, but a hypothesis. It is a theory about the cause of observed phenomena that generates predictions for contexts not yet observed.

Our nomenclature also allows us to state our thesis clearly. The term "endowment effect" can make it difficult to distinguish criticisms of the theory from denials of the phenomena it attempts to explain. To reject endowment theory is

5. See infra Part I.B.

6. See, e.g., David Markell et al., What Has Love Got to Do With It?: Sentimental Attachments and Legal Decision-Making, 57 VILL. L. REV. 209, 217 (2012) ("Endowment effect is a term that is used to describe the phenomenon by which individuals value what they have just come to possess more than their expressed value for the item prior to the moment of possession.").

7. Russell Korobkin's recent survey of the literature provides an example. Korobkin writes that "loss aversion is an empirical finding rather than a psychological explanation." Russell Korobkin, Wrestling With the Endowment Effect, or How to Do Law and Economics Without the Coase Theorem 16 (UCLA Sch. of Law, Law \& Econ. Research Paper Series, Paper No. 13-10, 2013), available at http://papers.ssrn.com/sol3/papers.cfm?abstract_id=2289574. Korobkin then goes on to describe four potential explanations for loss aversion: attachment to endowments, transactional disutility, regret avoidance, and attention, which refers to the order in which an individual considers costs and benefits of a potential change in status. See id. at 16-22. The economics literature, however, characterizes these four explanations as alternatives to loss aversion, which is the simple notion that individuals experience losses differently than gains regardless of the context. See, for example, Ericson and Fuster's recent review of the relevant economics literature. Keith M. Marzilli Ericson \& Andreas Fuster, The Endowment Effect (Nat'l Bureau of Econ. Research Working Paper Series, Paper No. 19384, 2013) (on file with authors). 
not to deny that ownership, or phenomena commonly associated with ownership, can sometimes affect preferences. It is simply to reject the hypothesis that ownership alone does so in the generic and unmediated way described by endowment theory. Calling endowment theory what it is - a theory-makes this clear.

\section{A. Early Critics of Coase: Ownership, Preferences, and Exogeneity}

Our story begins some years before the appearance of endowment theory. During the 1970s, many young legal scholars began to apply neoclassical microeconomics systematically to the analysis of legal problems. ${ }^{8}$ Among the central premises of that neoclassical legal economic analysis was the exogeneity of preferences - the assumption that what people want does not depend on what the law is. The premise is in part a simplifying one. By taking the idea of individual preferences as a given and adding a few assumptions about how they are structured and manifest themselves, the theorist can generate powerful predictions about how one or another legal rule will influence individuals' behavior. But the exogeneity assumption can also express a normative commitment. Describing preferences as coming from outside of the law allows one to think of the law as a tool to help people, individually or collectively, better satisfy those preferences. Taking preferences as given, law can correct, or at least minimize, imperfections in markets or other distributive systems that prevent individuals from maximizing preference satisfaction. Neoclassical economic analysis treats preferences as a polestar for charting the law's course, and a polestar works only if it remains fixed as the ship moves under it.

The methodological importance of exogeneity for economic analysis does not presuppose, much less entail, descriptive accuracy. There are a number of reasons to think that the exogeneity assumption does not describe how preferences actually operate. Because people are social creatures, for example, their social world shapes their preferences. The law is an important part of that social world. ${ }^{9}$ We also know from everyday experience that people rationally change their preferences in light of their life options and that the law plays an important part in determining those options. ${ }^{10}$

8. See Steven M. Teles, The Rise of the Conservative Legal Movement: The BATTLE FOR CONTROL OF THE LAW 181-219 (2008) (describing the early history of the law and economics movement and its attractiveness to young legal scholars).

9. See 2 JÜRGEN HABERMAS, THE THEORY OF COMMUNICATIVE ACTION: LIFEWORLD AND SYSTEM: A CRITIQUE OF FUNCTIONALIST REASON (Thomas McCarthy trans., Beacon Press 1987) (1981).

10. See JON ELSTER, SOUR GRAPES: STUDIES IN THE SUbVERSION OF RATIONALITY (1983). 
In legal scholarship, several early and influential critics of the exogeneity assumption emphasized instead the effects of entitlements on people's preferences. The reason was Coase. In 1960, Ronald Coase demonstrated the value of thinking of legal rules as setting entitlements. ${ }^{11}$ Laws do not merely establish duties and correlative rights. They grant rightsholders an entitlement to the duty's performance, which those rightsholders might sell or trade. Thus if the law gives homeowners the right to clean air, it might also allow them to sell that right to a neighboring factory that wants to pollute. If the factory has the right to pollute, it might sell that right to neighboring homeowners who want clean air. Viewed from this perspective, questions of legal design are ultimately questions of who gets the entitlement and how it should be protected. ${ }^{12}$ If the goal is to maximize preference satisfaction, the law should seek to get legal entitlements into the hands of those who value them most in the cheapest way possible, that is, with the lowest transaction costs possible.

This Coasian framework suggests an alternative formulation of the exogeneity assumption: The value a person assigns to a legal entitlement, such as the right to clean air or the right to pollute, does not depend on whether the law has given it to her. And in fact this is a central premise of Coase's famous theorem, which says that absent transaction costs, no matter to whom the law first assigns an entitlement, it will be traded until it ends up in the hands of the person who values it most. Coase's argument that "the ultimate result . . . is independent of the legal position" ${ }^{13}$ works only if the initial assignment of entitlements does not influence the value people assign to them.

Coase's enormous influence on economic legal scholarship explains why some early critics of the exogeneity assumption focused on entitlements. Mark Kelman's 1979 article, Consumption Theory, Production Theory, and Ideology in the Coase Theorem, led the way. ${ }^{14}$ Building on examples borrowed from Richard Thaler's then-forthcoming paper, Toward a Positive Theory of Consumer Choice, ${ }^{15}$ Kelman argued that in many situations the amount one is willing to accept to give up an entitlement one already has exceeds the amount one is willing to pay to obtain it. A professor who buys a bottle of wine for five dollars might, after it unexpectedly increases in value, drink the wine rather than sell it for one-

11. R. H. Coase, The Problem of Social Cost, 3 J.L. \&ECON. 1 (1960).

12. See Guido Calabresi \& A. Douglas Melamed, Property Rules, Liability Rules, and Inalienability: One View of the Cathedral, 85 HARV.L. REV. 1089 (1972).

13. Coase, supra note 11 , at 8 .

14. Mark Kelman, Consumption Theory, Production Theory, and Ideology in the Coase Theorem, 52 S. CAL. L. REV. 669 (1979) [hereinafter Kelman, Consumption Theory]; see also Mark Kelman, Choice and Utility, 1979 WIS. L. REV. 769.

15. Thaler, supra note 1. 
hundred dollars, though he would never have paid more than thirty-five dollars for the bottle. ${ }^{16}$ Similarly, Kelman observed that people refuse to sell homes that have "appreciated in value" beyond what they would be willing to pay for a new home. ${ }^{17}$ Kelman also pointed to emerging empirical evidence of gaps between willingness to pay and willingness to accept. In surveys, people reported very different amounts of money that they would be willing to pay to avoid a disease versus what they would be willing to accept to be exposed to it. ${ }^{18}$ And after the abolition of the reserve clause in professional baseball, there was much less player movement than might have been expected. ${ }^{19}$ Kelman marshaled these and other examples to argue that abstract legal entitlements - the right to clean water, or to damages in tort-probably also affect people's valuations. Contra Coase, "the long-term goals of the parties depend in part on the choice of law." ${ }^{20}$

We are interested less in Kelman's claim that entitlements affect willingness to trade than in his argument for it. The point of Kelman's 1979 article was primarily critical. His goal was to show that because the Coasian model relies on a number of simplifying assumptions, it is likely to generate false predictions. Such an argument required only a showing that entitlements often affect willingness to trade, not a systematic account of why they do so. ${ }^{21}$ Still, Kelman suggested a number of explanations for the reluctance to trade. These included social expectations that create a presumption against selling; ${ }^{22}$ a tendency to treat opportunity and out-of-pocket costs differently; ${ }^{23}$ wealth effects, which cause people to treat increases and decreases in income differently; ${ }^{24}$ the psychological need to withdraw certain spheres of activity from the market-based calculation,

16. Kelman, Consumption Theory, supra note 14, at 678-79. At places in the article Kelman suggests that entitlements can affect people's actual preferences, and not just expressions of preference, or willingness to trade. See, e.g., id. at 678 ("[G]oals of the parties depend in part on the choice of law." (emphasis added)); id. at 680 ("Income that the person could realize is worth less than the income that the person already has realized." (emphasis added)); id. at 696 ("[T]he legal liability rule would affect . . . the ways in which consumers would value alternative states." (emphasis added)). The distinction is a subtle one, and we cannot fault Kelman for failing to make the distinction consistently in this groundbreaking piece. And Kelman is correct that, for the purposes of his critical argument, "it does not matter whether the behavior manifested by the economic actors that have been discussed is rational or irrational, explicable or inexplicable." Id. at 685; see also Thaler, supra note 1, at 43-44.

17. Kelman, Consumption Theory, supra note 14, at 679 n.35.

18. See id. at 682; see also Thaler, supra note 1, at 43-44.

19. Kelman, Consumption Theory, supra note 14, at 683-85; see also Thaler, supra note 1, at 46-47.

20. Kelman, Consumption Theory, supra note 14, at 677-78.

21. See id. at 685 .

22. Id. at 687.

23. Id. at $688-89$.

24. Id. at 689-91. 
or to close transactions; ${ }^{25}$ simple conservatism; ${ }^{26}$ and a habit of deference to the law and its assignment of entitlements. ${ }^{27}$ Kelman's critique of Coase did not rest on a single phenomenon but identified a constellation of causes that together work to generate gaps between willingness to pay and willingness to accept.

Kelman's complex account of willingness-to-trade asymmetries provided a template for other critics of neoclassical economic analysis. In his 1981 article, Cost-Benefit Analysis of Entitlement Problems: A Critique, Duncan Kennedy summarized Kelman's several explanations, adding that gaps might also be explained by the way that the act-omission distinction frames decisions about aiding others. "[P] eople typically experience a 'duty to abstain from acts that cause suffering' that is much more intense than the 'duty to act affirmatively to prevent suffering.' If this is the case, we may get substantial offer-asking differences with respect to rights to hurt others." ${ }^{28}$ In his 1986 article, Legal Interference With Private Entitlements, Cass Sunstein identified five separate causes of "endowment effects" (note the use of the plural): the experience and increased knowledge that come with ownership; bargaining strategies, which often recommend asking for more than one's true value; wealth effects; people's tendency to value received income more than opportunity income; and self-affirmance that comes with valuing what one owns as distinguished from what one does not. ${ }^{29}$ Like Kelman's 1979 piece, Kennedy's and Sunstein's articles were primarily critical. Both sought to raise doubts about the descriptive adequacy of neoclassical economic theories of the law. Like Kelman, their primary concern was to show that Coasian bargaining does not capture how the world actually works. These critics were playing Hamlet to economists' Horatio. Their argument was in essence that there were more things in heaven and earth than were dreamt of in the economists' philosophy.

\section{B. Endowment Theory}

At the same time that Kelman, Kennedy, and Sunstein were mounting an entitlement-based critique of neoclassical legal economic analysis, other legal

25. Id. at 691-93.

26. Id. at 693-94.

27. Id. at 695 .

28. Duncan Kennedy, Cost-Benefit Analysis of Entitlement Problems: A Critique, 33 STAN. L. REV. 387, 402 (1981).

29. Cass R. Sunstein, Legal Interference With Private Preferences, 53 U. CHI. L. REV. 1129, 1150-51 (1986). Unlike both Kelman and Kennedy, Sunstein consistently puts the point in terms of effects on preferences themselves, rather than willingness to trade. See, e.g., id. at 1150 ("Social psychologists have demonstrated that people sometimes value things once they have them much more highly than they value the same things when they are owned by others."). 
scholars were finding new evidence of ownership's apparent effects on willingness to trade, and psychologists were working out new theories to explain those phenomena. The theory that had the most influence on legal scholarship was what we call "endowment theory."

The earliest version of endowment theory can be found in Richard Thaler's 1980 article, Toward a Positive Theory of Consumer Choice. ${ }^{30}$ Recall that Kelman's 1979 critique of Coase borrowed many of its examples from Thaler. But whereas Kelman identified a constellation of causes, Thaler's 1980 article proposed a single one. Thaler's account modified Daniel Kahneman and Amos Tversky's prospect theory. ${ }^{31}$ Prospect theory posits that, contrary to the predictions of expected utility theory, when deciding how to act, individuals weigh potential losses-shifts in a negative direction from some reference point-more heavily than potential gains of the same objective magnitude. In short, under conditions of uncertainty, people are loss averse. The Kahneman-Tversky thesis can be represented as a kink in the "value" function at the reference point: ${ }^{32}$

Figure 1. Prospect Theory Value Function

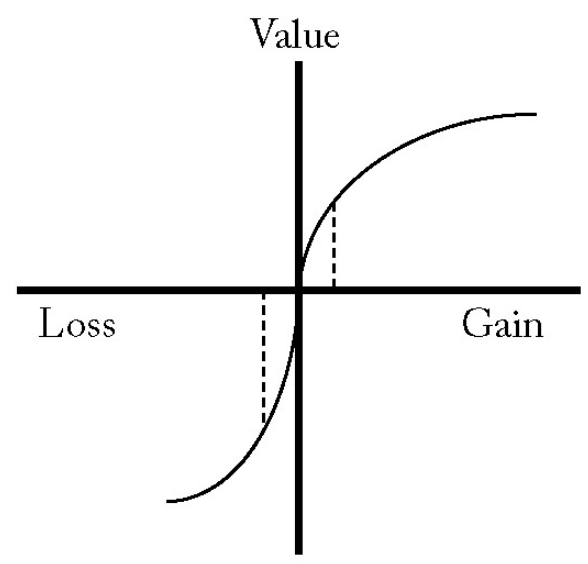

The horizontal axis measures the objective magnitude of the change away from the reference point (the origin), and the vertical measures the value gained or lost as a result of the change.

30. Thaler, supra note 1.

31. Daniel Kahneman \& Amos Tversky, Prospect Theory: An Analysis of Decision Under Risk, 47 ECONOMETRICA 263 (1979).

32. Tversky \& Kahneman, supra note 1, at 1040. 
Prospect theory was developed to explain decisions individuals make when they face risk, such as the decision whether to purchase a share of Apple stock or a lottery ticket. In an effort to apply the theory to explain choices made in riskfree contexts, such as the decision over whether to purchase a candy bar for consumption, Thaler drew on two of the theory's assumptions related to the general features of preferences-reference dependence and loss aversion. ${ }^{33}$ Prospect theory does not specify when subjects perceive a change as a loss or as a gain. It does not say what sets the reference point. Thaler's suggestion in the 1980 article was that the reference point was determined in part by a person's endowments-by what she owns. "[G]oods that are included in the individual's endowment will be more highly valued than those not held in the endowment . . . because removing a good from the endowment creates a loss while adding the same good (to an endowment without it) generates a gain." ${ }^{34}$ The result, Thaler argued, would be a gap between what people would be willing to pay for a good they did not have (WTP) and what they would be willing to accept to part with it (WTA). Because parting with a good is perceived as a loss and obtaining it is seen as a gain, people's WTA would be systematically higher than their WTP. Thaler christened this WTA-WTP gap the "endowment effect." 35

In 1980, there was little widely known, nonanecdotal evidence to support the existence of WTA-WTP gaps, much less the hypothesis that they resulted from loss aversion. ${ }^{36}$ This changed over the course of the next decade. Some of the earliest evidence came from environmental economists and lawyers and antedated Thaler's 1980 article. In the 1970s, Congress passed several laws that required environmental regulators to use cost-benefit analysis. ${ }^{37}$ In order to perform that analysis, regulators needed to assign dollar values to environmental goods for which no market existed. They attempted to generate those values using contingent-valuation surveys, in which subjects were asked to put a hypothetical dollar value on environmental goods such as the protection of wetlands or unpolluted air. To their surprise, many surveyors observed large gaps in reported valuations depending on whether the question was phrased in terms of how much a subject would be willing to pay to prevent an environmental harm or in terms of how much she would be willing to accept to permit the same

\footnotetext{
33. Thaler, supra note 1 , at 41-43.

34. Id. at 44 .

35. Id.

36. Id. at 45 .

37. For some of the relevant legal framework, see Daniel S. Levy \& David Friedman, The Revenge of the Redwoods? Reconsidering Property Rights and the Economic Allocation of Natural Resources, $61 \mathrm{U}$. CHI. L. REV. 493, 497-506 (1994).
} 
harm. ${ }^{38}$ A 1974 survey of duck hunters, for example, showed a hypothetical willingness to pay an average of $\$ 247$ to protect wetlands for hunting, but a hypothetical willingness to accept, on average, no less than $\$ 1044$ to lose the ability to hunt there. ${ }^{39}$ These observed WTA-WTP gaps generated a substantial literature among environmental economists on the question of which measure costbenefit analyses should use. ${ }^{40}$

In the early 1980s, experimental psychologists and economists began asking whether laboratory studies could produce similar WTA-WTP gaps. An obvious limitation of contingent-valuation surveys was that their questions were purely hypothetical. They asked how much a person would pay to protect or accept to lose an environmental good. Using goods of lesser value in the laboratory, experimenters developed methods to elicit binding valuations. ${ }^{41}$ In one of the first such studies, published in $1984,{ }^{42}$ Knetsch and Sinden gave half their subjects lottery tickets and the other half $\$ 2$ in cash. Subjects were told that the lottery winner would be able to choose between two prizes, such as a $\$ 70$ bookstore gift certificate and $\$ 50$ in cash. Ticket holders were then given a choice between keeping the ticket and selling it for $\$ 2$; non-ticket holders were given an opportunity to buy a ticket for $\$ 2$. Knetsch and Sinden hypothesized that once deci-

38. For overviews of these studies, see R. G. CUMMINGS ET AL., VALUING ENVIRONMENTAL GOODS: AN ASSESSMENT OF THE CONTINGENT VALUATION METHOD (Rowman \& Allanheld 1986); Elizabeth Hoffman \& Matthew L. Spitzer, Willingness to Pay vs. Willingness to Accept: Legal and Economic Implications, 71 WASH. U. L.Q. 59, 66-69 (1993); Cass R. Sunstein, Endogenous Preferences, Environmental Law, 22 J. LEGAL STUD. 217, 225-27 (1993); Russell Korobkin, Note, Policymaking and the Offer/Asking Price Gap: Toward a Theory of Efficient Entitlement Allocation, 46 STAN. L. REV. 663, 667-68 (1994).

39. JUDD HAMMACK \& GARDNER MALLARD BROWN, JR., WATERFOWL AND WETLANDS: TOWARD BIOECONOMIC ANALYSIS 26-27 (1974).

40. See, e.g., Herbert Hovenkamp, Legal Policy and the Endowment Effect, 20 J. LEGAL STUD. 225 (1991); Levy \& Friedman, supra note 37; Richard S. Markovits, Duncan's Do Nots: Cost-Benefit Analysis and the Determination of Legal Entitlements, 36 STAN. L. REV. 1169 (1984); Murray B. Rutherford et al., Assessing Environmental Losses: Judgments of Importance and Damage Schedules, 22 HARV. ENVTL. L. REV. 51 (1998); Douglas R. Williams, Valuing Natural Environments: Compensation, Market Norms, and the Idea of Public Goods, 27 CONN. L. REV. 365 (1995); Korobkin, supra note 38; John K. Horowitz et al., Behavioral Foundations of Environmental Economics and Valuation (Univ. of Alaska Anchorage Dep't of Econ., Working Paper No. 201203, 2012).

41. By binding valuations, we mean valuations reported in a context in which potential buyers might be required to purchase goods—and potential sellers might be required to sell their goods-based on their reported valuations.

42. Jack L. Knetsch \& J. A. Sinden, Willingness to Pay and Compensation Demanded: Experimental Evidence of an Unexpected Disparity in Measures of Value, 99 Q.J. ECON. 507 (1984) [hereinafter Knetsch \& Sinden, Willingness to Pay]. For examples of other early laboratory experiments, see Robin Gregory \& Lita Furby, Auctions, Experiments and Contingent Valuation, 55 PUB. CHOICE 273 (1987) and Jack L. Knetsch \& J. A. Sinden, The Persistence of Evaluation Disparities, 102 Q.J. ECON. 691 (1987). 
sions were binding - once subjects actually had to trade rather than merely report hypothetical valuations - the WTA-WTP gap would disappear. Their prediction was wrong. More ticket holders ended up with tickets than did potential buyers, suggesting that ticket holders' WTA was, on average, higher than nonticket holders' WTP. Knetsch and Sinden argued that, although the causes of the gap were not clear, the experiment provided additional empirical evidence for Thaler's endowment theory. ${ }^{43}$ Many subsequent experiments confirmed the existence of a WTA-WTP gap and explored various aspects of it. ${ }^{44}$

The legal literature in the 1980s took some account of this new data. But the real turning point came with a trio of articles by experimentalists that appeared in 1989, 1990, and 1991.

In his 1989 article, The Endowment Effect and Evidence of Nonreversible Indifference Curves, Jack Knetsch described a new sort of experiment to test Thaler's hypothesis. ${ }^{45}$ Rather than asking subjects to assign a dollar value to goods, Knetsch gave them the opportunity to exchange goods of roughly equal value. Each subject in one group received a mug and then the opportunity to trade it for a candy bar. In a separate session, different subjects initially received a candy bar and an option to trade it for a mug. Of the seventy-six subjects initially given mugs, 89 percent chose to keep the mug rather than exchange it for a candy bar. The possibility that subjects simply preferred the mugs to the candy bars was ruled out by the fact that, of the 87 subjects initially given candy bars, 90 percent chose to keep the candy bar rather than exchange it for a mug. Whereas contingent-valuation surveys in the field and price experiments in the laboratory had elicited WTA-WTP gaps as measured in dollars, Knetsch's exchange experiment showed a pure exchange asymmetry-different outcomes in posttrade ownership that apparently resulted from the random assignment of entitlements at the outset.

Knetsch's 1989 study was followed in 1990 by Kahneman, Knetsch, and Thaler's Experimental Tests of the Endowment Effect and the Coase Theorem. ${ }^{46}$ Although this article reported the results of several new experiments employing novel methods, its real importance lay in the authors' theoretical claims. In the decade since Thaler's 1980 article, there had emerged considerable empirical evi-

43. Knetsch \& Sinden, Willingness to Pay, supra note 42 , at 516.

44. For overviews, see Hoffman \& Spitzer, supra note 38, at 69-85. See also John K. Horowitz \& Kenneth E. McConnell, A Review of WTA/WTP Studies, 44 J. ENVTL. ECON. \& MGMT. 426 (2002).

45. Jack L. Knetsch, The Endowment Effect and Evidence of Nonreversible Indifference Curves, 79 AM. ECON. REV. 1277 (1989).

46. Daniel Kahneman et al., Experimental Tests of the Endowment Effect and the Coase Theorem, $98 \mathrm{~J}$. POL. ECON. 1325 (1990). 
dence that WTA-WTP gaps were a common occurrence. ${ }^{47}$ And Knetsch's recent article had reported observed asymmetries in pure exchange transactions. ${ }^{48}$ What was not yet clear was what caused these phenomena. Picking up on Thaler's earlier thesis, Kahneman, Knetsch, and Thaler hypothesized that "many discrepancies between WTA and WTP, far from being a mistake, reflect a genuine effect of reference positions or preferences," and that the effect was a manifestation of the more general phenomenon of loss aversion, as described by prospect theory. ${ }^{49}$ More specifically, they hypothesized that WTA-WTP gaps would appear in the absence of other potential causes, such as subject confusion, strategic bargaining habits, reluctance to engage in market transactions, wealth effects, and trophy effects. To test that hypothesis, they ran a series of experiments designed to rule out those alternative explanations. ${ }^{50}$ In all the experiments, statistically significant WTA-WTP gaps or exchange asymmetries were observed. ${ }^{51}$ For the moment, Kahneman, Knetsch, and Thaler's methods for testing their hypothesis are of less interest to us than the authors' interpretation of the results: "The evidence presented in this paper supports what may be called an instant endowment effect. the value that an individual assigns to such objects as mugs, pens, binoculars, and chocolate bars appears to increase substantially as soon as that individual is given the object." ${ }^{52}$ Whereas early legal critics of Coase had suggested many causes for the tendency to value what one has more than what one does not, Kahneman, Knetsch, and Thaler suggested that a single cause was sufficient to produce the effect: ownership, or "endowment." 53 This is what we call "endowment theory."

Kahneman, Knetsch, and Thaler's 1990 article also argued that endowment theory presented challenges for neoclassical economic theory. Most significantly from the standpoint of legal scholars, they described the implications for the Coase theorem:

Contrary to the assumptions of standard economic theory that preferences are independent of entitlements, the evidence presented here indicates that people's preferences depend on their reference positions.

47. See id. at $1326-28$.

48. See id. at 1341-42.

49. Id. at $1326-28$.

50. See id. at 1328-29.

51. See id. at 1327 tbl.1.

52. Id. at 1342 (emphasis added).

53. Id. ("While long-term endowment effects could be explained by sentimental attachment or by an improved technology of consumption..., the differences in preference or taste demonstrated by more than 700 participants in the experiments reported in this paper cannot be explained in this fashion."). 
Consequently, preference orderings are not defined independently of endowments: good A may be preferred to B when A is part of an original endowment, but the reverse may be true when initial reference positions are changed. ${ }^{54}$

Kahneman, Knetsch, and Thaler also suggested several places where the endowment effect could be seen at work in the world: in the reluctance of people to resell sporting event tickets purchased through a lottery, in firms' reluctance to divest themselves of unproductive assets, and in legal rules that favor possessors over other claimants. ${ }^{55}$

The third influential article was Tversky and Kahneman's 1991 Loss Aversion in Riskless Choice: A Reference-Dependent Model. ${ }^{56}$ Although this article covered much of the same ground as the earlier pieces, it explicitly applied prospect theory to environments of riskless choice, essentially formalizing endowment theory. Specifically, Tversky and Kahneman posited that endowments operated to set the reference point, movement from which would be perceived either as a gain or a loss. ${ }^{57}$ Again the central claim was that endowment alone was sufficient to affect outcomes: "An immediate consequence of loss aversion is that the loss of utility associated with giving up a valued good is greater than the utility gain associated with receiving it." 58

\section{Endowment Theory in Legal Scholarship}

The influence of Kahneman, Knetsch, Thaler, and Tversky's trio of articles was immediate and considerable. A search of Westlaw's Journals and Law Reviews database finds 264 articles citing Kahneman, Knetsch, and Thaler's 1990 piece, 88 citing Tversky and Kahneman's 1991 article, and 63 citing Knetsch's 1989 article. Before 1990, only eleven articles in the database used the term "endowment effect." Between 1990 and 1995, 74 articles used the term, and from 1996 to 2000, 164 articles used it. Westlaw reports almost 1200 articles using the term between 1990 and today. ${ }^{59}$

54. Id. at 1343-44 (footnote omitted).

55. Id. at $1344-46$.

56. Tversky \& Kahneman, supra note 1.

57. See id. at 1040.

58. Id. at 1041 (emphasis added); see also id. at 1054 (arguing that loss aversion is an important component in the WTA-WTP gap, along with other potential causes such as income effect, strategic behavior, and the legitimacy of transactions).

59. All searches run on October 18, 2013. As measured by citations, the influence of the Kahneman, Knetsch, Thaler, and Tversky articles remains an order of magnitude lower than that of Coase's 1960 article, which has been cited 2876 times since 1989. 
But numbers alone do not tell the story. Endowment theory has generated a massive amount of legal scholarship and influenced even more of it. ${ }^{60}$ In 1994, Herbert Hovenkamp sought to recast earlier critics' arguments against exogenous preferences solely in terms of the endowment effect. Endowment theory sufficed to show the impossibility of a preference-based economic analysis of law.

[A] robust offer-ask disparity greatly decreases our confidence in the efficiency of private markets generally, at least if our efficiency goals are stronger than Pareto efficiency. It also decreases our confidence in the Coase Theorem as a mechanism for predicting the consequences of private bargaining over legal entitlements. Even more fundamentally, it constrains the policymaker's ability to use measures of value based on either observed willingness to pay or observed willingness to accept. Rather, value must be determined by means other than the observation of preferences. ${ }^{61}$

Along similar lines, in 1998 Christine Jolls, Cass R. Sunstein, and Richard Thaler, after describing recent price and exchange experiments, concluded that "[c]areful empirical study ... shows that the Coase theorem is not a tautology; indeed, it can lead to inaccurate predictions." ${ }^{2}$ Suggesting that economics should be judged "on the quality of its predictions," Jolls, Sunstein, and Thaler argued that behavioral economics, including endowment theory, provided a better approach than did the assumptions of neoclassical economics. ${ }^{63}$

In addition to these arguments in the register of theory, many legal scholars argued that endowment theory had practical implications for legal design. These arguments commonly implicitly assumed what Sunstein put into words. For legal scholars, "the most important source of reference points is the law: Where has the legal system placed the initial entitlement?" ${ }^{64}$ In an early example of the genre, David Cohen and Jack Knetsch argued that endowment theory explained and justified legal rules that favored possessory interests such as the adverse possession rule, limitations on the recovery of lost profits and the economic loss rule, judicial reluctance to enforce executory contract modifications absent consideration, the nonenforcement of gratuitous promises, and restrictions on creditors'

60. For a good overview, see Russell Korobkin, The Endowment Effect and Legal Analysis, 97 NW. U. L. REV. 1227 (2003).

61. Herbert Hovenkamp, The Limits of Preference-Based Legal Policy, 89 NW. U. L. REV. 4, 58 (1994).

62. Christine Jolls et al., A Behavioral Approach to Law and Economics, 50 STAN. L. REV. 1471, 1483 (1998).

63. Id. at 1484

64. Cass R. Sunstein, Behavioral Analysis of Law, 64 U. CHI. L. REV. 1175, 1180 (1997). 
repossession rights. ${ }^{65}$ All could "be explained as manifestations of the idea that possession losses are much more important than foregone gains, and the law takes such real differences into account." ${ }^{6}$ Jolls, Sunstein, and Thaler also suggested concrete policy implications. The endowment effect explained why winning parties chose not to contract around court orders; ${ }^{67}$ it supported mandatory terms in employment contracts that gave employees benefits those employees would not choose to buy but that they would value highly once possessed; ${ }^{68}$ and it explained the rule against prior restraint on speech, since prosecutors would otherwise experience their right to enforce the injunction as an endowment. ${ }^{69}$ Russell Korobkin deployed endowment theory to argue that we should expect the endowment effect to be stronger when an entitlement is protected by an easily predictable rule rather than a discretionary standard. Because the endowment effect tends to reduce trade, "standards might be more likely than rules to facilitate efficient private allocations of entitlements in low transaction-cost settings." 70

Legal scholars also worked to further develop endowment theory by designing and implementing experiments to test precisely when and why endowment effects occur. It will be important for our argument in Part III to distinguish between two varieties of such experiments, which we call "simple experiments" and "hypothetical experiments." Simple experiments put subjects in stripped-down settings designed to isolate a single cause in order to test a general hypothesis. Thaler's mug-and-candy-bar experiments are paradigmatic. Because effective testing of economic theories requires that subjects have a stake in the outcome, ${ }^{71}$ simple experiments commonly provide subjects the opportunity to engage in an actual sale or exchange rather than asking what they would do in a hypothetical transaction. Starting in the 1990s, legal scholars, sometimes working with exper-

65. David Cohen \& Jack L. Knetsch, Judicial Choice and Disparities Between Measures of Economic Values, 30 OsGOODE HALL L.J. 737 (1992).

66. Id. at 741 (footnote omitted).

67. Jolls et al., supra note 62, at 1497-1501.

68. Id. at $1505-08$.

69. Id. at 1517 .

70. Russell B. Korobkin, Behavioral Analysis and Legal Form: Rules vs. Standards Revisited, 79 OR. L. REV. 23, 52 (2000). But see Dale A. Nance, Rules, Standards, and the Internal Point of View, 75 FORDHAM L. REV. 1287 (2006) (criticizing Korobkin's argument).

71. Some evidence suggests that the lack of stakes does not impact choice under some conditions. See, e.g., Colin F. CAMERER, Behavioral GAME TheOry: EXPERIMENTS IN STRATEGiC INTERACTION 38-40 (2003). If results vary, however, more weight should be placed on the results produced by experiment designs that account for all assumptions of the theory, including actual stakes. The hypothetical nature of early gaps experiments was one of the first alternative explanations to be tested. See Knetsch \& Sinden, Willingness to Pay, supra note 42. 
imentalists, began to use simple experiments to test endowment theory further. ${ }^{72}$ George Loewenstein and Samuel Issacharoff, for example, conducted an experiment with mugs to test whether the way people acquire an endowment affects the strength of the endowment effect. ${ }^{73}$ They found larger WTA-WTP gaps in subjects who were given a mug as a reward for good performance than in those who were randomly assigned the mug. Jennifer Arlen, Matthew Spitzer, and Eric Talley asked whether agents, as distinguished from principals, exhibit WTA-WTP gaps. They gave undergraduates mugs that the subjects could sell and told some of them to pretend to be deciding as agents for a hypothetical firm. ${ }^{74}$ Arlen, Spitzer, and Talley found that "situating subjects in an agency context significantly dampens the magnitude (and perhaps even the existence) of the endowment effect." 75 Christopher Buccafusco and Christopher Sprigman gave or asked subjects to write a haiku or paint a picture to test endowment effects in nonrival goods and the effect of authorship on WTA-WTP gaps. ${ }^{76}$

Others used experimental methods to test expressly legal questions related to endowment theory by using hypothetical experiments. ${ }^{77}$ Whereas simple experiments employ highly stylized forms of exchange to isolate the effect of ownership from other potential causes, hypothetical experiments are designed to test ownership's effects in familiar contexts, typically by presenting subjects in the laboratory with a detailed hypothetical transaction that might occur in the world

72. In addition to the articles discussed in this paragraph, see Owen D. Jones \& Sarah F. Brosnan, Law, Biology, and Property: A New Theory of the Endowment Effect, 49 WM. \& MARY L. REV. 1935 (2008), and Sarah F. Brosnan et al., Endowment Effects in Chimpanzees, 17 CURRENT BIOLOGY 1704 (2007), which discusses testing for the endowment effect in chimpanzees.

73. George Loewenstein \& Samuel Issacharoff, Source Dependence in the Valuation of Objects, 7 J. BEHAV. DECISIONMAKING 157 (1994).

74. Jennifer Arlen et al., Endowment Effects Within Corporate Agency Relationships, 31 J. LEGAL STUD. 1 (2002).

75. Id. at 5 .

76. Christopher Buccafusco \& Christopher Jon Sprigman, The Creativity Effect, 78 U. CHI. L. REV. 31 (2011); Christopher Buccafusco \& Christopher Sprigman, Valuing Intellectual Property: An Experiment, 96 CORNELL L. REV. 1 (2010). But see also Ofer Tur-Sinai, The Endowment Effect in IP Transactions: The Case Against Debiasing, 18 MiCH. TelECOMM. \& TECH. L. REV. 117 (2011) (criticizing Buccafusco and Sprigman's interpretation of their results).

77. In addition to the articles discussed in this paragraph, see Jeremy A. Blumenthal, Group Deliberation and the Endowment Effect: An Experimental Study, 50 HoUS. L. REV. 41 (2012) (using the Rachlinski \& Jourden hypotheticals, infra note 82, to test the effects of group decisionmaking on endowment effect); Richard R.W. Brooks et al., Framing Contracts: Why Loss Framing Increases Effort, 168 J. INSTITUTIONAL \& THEORETICAL ECON. 62 (2012) (asking student subjects to play the role of a supplier of circuit boards and testing effects of framing possible outcomes as gains or as losses); Jonathan Remy Nash, Packaging Property: The Effect of Paradigmatic Framing of Property Rights, 83 TUL. L. REV. 691 (2009) (surveying incoming law students to test the consequences for the endowment effect of characterizing property as a discrete asset versus a bundle of rights). 
outside of the laboratory and asking how they would respond to it. Russell Korobkin, for example, asked law students to engage in hypothetical negotiations to test whether negotiating parties might prefer default terms or terms on form contracts, as distinguished from terms that required negotiation. ${ }^{78} \mathrm{He}$ found such a preference in his data and argued that the existence of such a status-quo bias was a reason to adopt majoritarian and tailored defaults, or nonenforcement defaults to avoid the effect altogether. ${ }^{79}$ Cass Sunstein has also attempted to test the effects of contract defaults empirically, asking one group of law students the minimum they would accept to lose two weeks of vacation and another group how much they would pay to gain two extra weeks. ${ }^{80}$ Observing a WTA-WTP gap, Sunstein concluded:

The switch of the entitlement might well make a difference simply by virtue of the endowment effect- the effect of the initial allocation of the right on people's valuations, possibly employers and almost certainly workers. When the endowment effect is at work, preferences and valuations are affected by the initial allocation of the entitlement; contrary to the Coase Theorem, there is no prelegal "preference" from which the legal system can work. ${ }^{81}$

Jeffrey Rachlinski and Forest Jourden asked undergraduates to pretend they were trustees of a land trust and examined whether the endowment effect was stronger when a right was protected by a liability rule or by a property rule. ${ }^{82}$ They found larger WTA-WTP gaps in entitlements protected by property rules. Like other legal scholars, they took their results to have significant policy implications:

If the endowment effect is properly viewed as an unwanted impediment to trade, or as a transaction cost, then these results add to the case against property rules. Removing the right to injunctive relief from a possession would eliminate the attachment that people feel for their rights, thereby facilitating trade. ${ }^{83}$

78. Russell Korobkin, Inertia and Preference in Contract Negotiation: The Psychological Power of Default Rules and Form Terms, 51 VAND. L. REV. 1583 (1998) [hereinafter Korobkin, Inertia and Preference]; Russell Korobkin, The Status Quo Bias and Contract Default Rules, 83 CORNELL L. REV. 608 (1998) [hereinafter Korobkin, The Status Quo Bias].

79. Korobkin, The Status Quo Bias, supra note 78, at 668.

80. Cass R. Sunstein, Switching the Default Rule, 77 N.Y.U.L. REV. 106 (2002).

81. Id. at 109 (footnotes omitted).

82. Jeffrey J. Rachlinski \& Forest Jourden, Remedies and the Psychology of Ownership, 51 VAND. L. REV. 1541 (1998). But see Daphna Lewinsohn-Zamir, The Choice Between Property Rules and Liability Rules Revisited: Critical Observations From Behavioral Studies, 80 TEX. L. REV. 219, 254 (2001) (criticizing Rachlinski \& Jourden's analysis).

83. Rachlinski \& Jourden, supra note 82, at 1574-75. 
Finally, and perhaps most significantly, the influence of endowment theory can be seen in its ubiquity in legal policy analysis. In addition to the detailed policy arguments described above, legal scholars have identified a dizzying array of entitlements as perhaps triggering the endowment effect. A trip through the law reviews suggests that the endowment effect might be at work in the ownership of homes and other personal property; ${ }^{84}$ in the possession of a residence during the mandatory three-day rescission period or of goods during a return period; ${ }^{85}$ in the ownership experience of an adverse possessor, as distinguished from that of the owner of record ${ }^{86}$ in a landowner's present right to build on her property; ${ }^{87}$ in rights to use natural resources such as water ${ }^{88}$ in a promisee's moral entitlement to performance; ${ }^{89}$ in a wide variety of default contract terms; ${ }^{90}$ in intellectu-

84. See, e.g., Susan Block-Lieb \& Edward J. Janger, The Myth of the Rational Borrower: Rationality, Behavioralism, and the Misguided "Reform" of Bankruptcy Law, 84 TEX. L. REV. 1481, 1553-54 (2006); Nestor M. Davidson, Property and Identity: Vulnerability and Insecurity in the Housing Crisis, 47 HARV. C.R.-C.L. L. REV. 119, 131 (2012); Zachary D. Kuperman, Note, Cutting the Baby in Half: An Economic Critique of Indivisible Resource Partition, 77 BROOK. L. REV. 263, 28586 (2011).

85. See, e.g., Jon D. Hanson \& Douglas A. Kysar, Taking Behavioralism Seriously: The Problem of Market Manipulation, 74 N.Y.U. L. REV. 630, 733-34 (1999); Christopher L. Peterson, “Warning: Predatory Lender"-A Proposal for Candid Predatory Small Loan Ordinances, 69 WASH. \& LEE L. REV. 893, 919-21 (2012); Lauren E. Willis, Decisionmaking and the Limits of Disclosure: The Problem of Predatory Lending: Price, 65 MD. L. REV. 707, 762 (2006).

86. See, e.g., Jeffrey Evans Stake, The Uneasy Case for Adverse Possession, 89 GEO. L.J. 2419, 245963 (2001).

87. See, e.g., Georgette C. Poindexter, Light, Air, or Manhattanization?: Communal Aesthetics in Zoning Central City Real Estate Development, 78 B.U. L. REV. 445, 495-97 (1998).

88. See, e.g., Todd S. Aagaard, Environmental Harms, Use Conflicts, and Neutral Baselines in Environmental Law, 60 DUKE L.J. 1505, 1552 (2011); Carol Necole Brown, Drinking From a Deep Well: The Public Trust Doctrine and Western Water Law, 34 FLA. ST. U. L. REV. 1, 16 (2006); Carol M. Rose, A Dozen Propositions on Private Property, Public Rights, and the New Takings Legislation, 53 WASH. \& LEE L. REV. 265, 295 (1996).

89. See, e.g., Ben Depoorter \& Stephan Tontrup, How Law Frames Moral Intuitions: The Expressive Effect of Specific Performance, 54 ARIZ. L. REV. 673, 711-13 (2012); Robert A. Prentice, "Law E" Gratuitous Promises, 2007 U. ILL. L. REV. 881, 917-18.

90. See, e.g., Eyal Zamir, The Inverted Hierarchy of Contract Interpretation and Supplementation, 97 COLUM. L. REV. 1710, 1760-61 (1997) (in general); see also, e.g., Benjamin Alarie, Dividend Entitlements and Intermediate Default Rules, 2 STAN. J.L. BUS. \& FIN. 135, 157-58 (2004) (terms governing insider trading); Michael D. Birnhack, Who Owns Bratz? The Integration of Copyright and Employment Law, 20 FORDHAM INTELL. PROP. MEDIA \& ENT. L.J. 95, 137-38 (2009) (penalty defaults favoring employee); David Millon, Piercing the Corporate Veil, Financial Responsibility, and the Limits of Limited Liability, 56 EMORY L.J. 1305, 1320-21 (2007) (shareholder limited liability); Brian JM Quinn, Shareholder Lawsuits, Status Quo Bias, and Adoption of the Exclusive Forum Provision, 45 U.C. DAVIS L. REV. 137, 175-82 (2011) (defaults in corporate charters). See also Korobkin, Inertia and Preference, supra note 78, and Korobkin, The Status Quo Bias, supra note 78, arguing that contract defaults are not entitlements per se but that they trigger the status quo bias. 
al property $;{ }^{91}$ in a beneficiary's rights under a trust; ${ }^{92}$ in a copyright holder's hypothetical right to the use of her work in parody $;{ }^{93}$ in control of a corporation; $;{ }^{94}$ in high corporate profits due to regulatory noncompliance; ${ }^{95}$ in risk assessment of securities; ${ }^{96}$ in the ownership of restricted stock by a manager, as distinguished from an option to purchase the same stock; ${ }^{97}$ in managers' attitudes toward a corporate merger after it has been announced; ${ }^{98}$ in emission rights under a capand-trade system; ${ }^{99}$ in tax benefits; ${ }^{100}$ in the timing of tax assessments; ${ }^{101}$ in the right to disability accommodations; ${ }^{102}$ in an existing employment position, as dis-

91. See, e.g., Michael Jacobs \& Alan Devlin, The Riddle Underlying Refusal-to-Deal Theory, 105 Nw. U. L. REV. COLlOQUY 1, 3 n.9 (2010); Christine Jolls \& Cass R. Sunstein, Debiasing Through Law, 35 J. Legal STUD. 199, 222 (2006); Mark A. Lemley, Contracting Around Liability Rules, 100 CALIF. L. REV. 463, 485-86 (2012).

92. See, e.g., Lee-ford Tritt, The Limitations of an Economic Agency Cost Theory of Trust Law, 32 CARDOZO L. REV. 2579, 2624-25 (2011).

93. See, e.g., Wendy J. Gordon, Market Failure and Intellectual Property: A Response to Professor Lunney, 82 B.U. L. REV. 1031, 1033 (2002); Wendy J. Gordon \& Daniel Bahls, The Public's Right to Fair Use: Amending Section 107 to Avoid the "Fared Use" Fallacy, 2007 UTAH L. REV. 619, 639-43; Guy Pessach, Israeli Copyright Law: A Positive Economic Perspective, 39 ISR. L. REV. 123, 151 (2006).

94. See, e.g., Lucian Arye Bebchuk \& Mark J. Roe, A Theory of Path Dependence in Corporate Ownership and Governance, 52 STAN. L. REV. 127, 141 (1999).

95. See, e.g., Vincent Di Lorenzo, Does the Law Encourage Unethical Conduct in the Securities Industry?, 11 FORDHAM J. CORP. \& FIN. L. 765, 794 (2006).

96. See, e.g., Tom C. W. Lin, A Behavioral Framerwork for Securities Risk, 34 SEATTLE U. L. REV. 325, 342-43 (2011).

97. See, e.g., Michael B. Dorff, The Group Dynamics Theory of Executive Compensation, 28 CARDOZO L. REV. 2025, 2064 (2007).

98. See, e.g., John C. Coates IV \& Guhan Subramanian, A Buy-Side Model of ME $\mathcal{A}$ A Lockups: Theory and Evidence, 53 STAN. L. REV. 307, 362-63 (2000).

99. See, e.g., Robert W. Hahn \& Robert N. Stavins, The Effect of Allowance Allocations on Cap-andTrade System Performance, 54 J.L. \& ECON. S267, S276-77 (2011).

100. See, e.g, Heather M. Field, Tax Elections E Private Bargaining, 31 VA. TAX REV. 1, 32-33 (2011); Rebecca M. Kysar, Lasting Legislation, 159 U. PA. L. REV. 1007, 1034-35 (2011); Stephanie Hunter McMahon, Political Hot Potato: How Closing Loopholes Can Get Policymakers Cooked, 37 J. LEGIS. 142, 167 (2012).

101. See, e.g., Tsilly Dagan, Itemizing Personhood, 29 VA. TAX REV. 93, 119-20 (2009) (discussing the effect of taxes on nonmarket goods, as distinguished from allowing deductions or providing credits for the surplus from market transactions); David Gamage \& Darien Shanske, Three Essays on Tax Salience: Market Salience and Political Salience, 65 TAX L. REV. 19, 57 (2011) (noting that taxes assessed at the time of a market decision are seen as part of the cost decision while taxes assessed after estate or other taxes after the transaction are seen as nonvoluntary extractions); Kyle D. Logue \& Joel Slemrod, Of Coase, Calabresi, and Optimal Tax Liability, 63 TAX L. REV. 797, 848-49 (2010) (comparing the experience of paying taxes at the end of the year with the experience of having taxes withheld in a paycheck); Edward J. McCaffery \& Jonathan Baron, Isolation Effects and the Neglect of Indirect Effects of Fiscal Policies, 19 J. BEHAV. DECISION MAKING 289, 289-90 (2006) (comparing hidden taxes with visible taxes).

102. See, e.g., Cass R. Sunstein, Cost-Benefit Analysis Without Analyzing Costs or Benefits: Reasonable Accommodation, Balancing, and Stigmatic Harms, 74 U. CHI. L. REV. 1895, 1900 (2007). 
tinguished from a potential one; ${ }^{103}$ in union representation; ${ }^{104}$ in a criminal defendant's right to trial; ${ }^{105}$ in judges' attitudes toward existing legal rules; ${ }^{106}$ in the assignment of a case for a judge $;{ }^{107}$ in bottle deposits; ${ }^{108}$ in solar access; ${ }^{109}$ in the school one's child attends; ${ }^{110}$ and in the ability to purchase alcohol at a low price. ${ }^{111}$

To be clear, in many of the above claims endowment theory is not essential to the author's argument. In some, the endowment effect is mentioned only in passing. In some, the claim is accompanied by qualifications about the need for further research or alternative explanations of the same phenomena. In some, it is easy to imagine what an alternative explanation would look like. And, in some, authors use the term "endowment effect" when they really mean loss aversion or prospect theory more generally.

But all this is just further evidence of contemporary legal scholars' remarkable readiness to appeal to endowment theory in formulating policy arguments. The widespread belief that ownership has an immediate effect on willingness to trade is directly traceable to endowment theory. Whether legal scholars understand it or not, it is that theory that licenses experimental psychologists' claims that ownership has generic unidirectional effect on willingness to trade. This widespread acceptance, be it implicit or explicit, of prospect theory as a general explanation of WTA-WTP gaps and exchange asymmetries has effectively flipped the presumption in the legal literature and invited legal scholars to apply

103. See, e.g., Richard Thompson Ford, Discounting Discrimination: Dukes v. Wal-Mart Proves That Yesterday's Civil Rights Laws Can't Keep up With Today's Economy, 5 HARV. L. \& POL'Y REV. 69, 81-82 (2011); Scott A. Moss \& Peter H. Huang, How the New Economics Can Improve Employment Discrimination Law, and How Economics Can Survive the Demise of the "Rational Actor," 51 WM. \& MARY L. REV. 183, 204-06 (2009); Nicole B. Porter, Reasonable Burdens: Resolving the Conflict Between Disabled Employees and Their Coworkers, 34 FLA. ST. U. L. REV. 313, 339-40 (2007).

104. See, e.g., Alan Bogg, The Democratic Aspects of Trade Union Recognition 206 (2009); Brishen Rogers, Passion and Reason in Labor Law, 47 HARV. C.R.-C.L. L. REV. 313, 34445 (2012).

105. See, e.g., Russell Covey, Reconsidering the Relationship Between Cognitive Psychology and Plea Bargaining, 91 MARQ. L. REV. 213, 220 (2007).

106. See, e.g., Goutam U. Jois, Stare Decisis Is Cognitive Error, 75 BROOK. L. REV. 63, 98-99 (2009).

107. See, e.g., Jeffrey W. Stempel, In Praise of Procedurally Centered Judicial Disqualification-And a Stronger Conception of the Appearance Standard: Better Acknowledging and Adjusting to Cognitive Bias, Spoliation, and Perceptual Realities, 30 REV. LITIG. 733, 748 (2011).

108. See, e.g., Ann E. Carlson, Recycling Norms, 89 CALIF. L. REV. 1231, 1294 (2001).

109. See, e.g., Troy A. Rule, Shadows on the Cathedral: Solar Access Laws in a Different Light, 2010 U. ILL. L. REV. 851, 885-86.

110. See, e.g., Susan L. DeJarnatt, School Choice and the (Ir) rational Parent, 15 GEO. J. ON POVERTY L. \&POL'Y 1, 40 (2008).

111. See, e.g., Lawrence Zelenak, The Puzzling Case of the Revenue-Maximizing Lottery, 79 N.C. L. REV. $1,33-34(2000)$. 
commonsense knowledge about how ownership sometimes affects preferences and willingness to trade to contexts in which common sense is a much less reliable guide. Early critics of the Coase theorem-Kelman, Kennedy, and early Sunstein-pointed to a collection of phenomena that can cause people to assign greater value to what they have than to what they do not have. In order to argue that a given legal entitlement was likely to affect people's preferences, one had to tell a story about why that entitlement was likely to result in a change in valuation. That story might include causes cognizable under traditional economic theory, such as wealth effects or increased knowledge about the object of the entitlement. It might involve biases or heuristics, such as buy-low/sell-high bar-

gaining habits. Or it might involve observations about the affective aspects of ownership, such as the attachment people feel toward some possessions, the felt need to remove some spheres of life from the marketplace, or the tendency to treat legal assignments as presumptively correct. The effect of endowment theory has been to flip the burden of persuasion. Legal scholars have read the theory as a license to assume, without explanation or argument, that virtually any legal entitlement will positively affect preferences, allowing them to jump straight to the policy implications. The endowment effect is "instant"112 and "hardwired," 113 a simple fact about how our brains work. And if it applies to ownership in general, then it applies to any legal entitlement-from an employee's attitude toward contract defaults, to a prosecutor's feelings about her power of prior restraint on speech, to a taxpayer's experience of taxes on nonmarket goods, to a security holder's feelings about stock as distinguished from options. Because the concept of a legal entitlement is so broad, flipping the presumption vastly expanded the reach of the familiar and intuitive idea that ownership can affect preferences, extending it to contexts in which we would otherwise have no reason to expect such an effect.

\section{Critical and Cautionary Voices}

Although endowment theory has had an enormous influence in legal scholarship, we do not want to give the impression that its reception has been entirely uncritical. We will not attempt here to survey or summarize everything that has been said in the law reviews about endowment theory. Instead we describe what, in our view, are a few of the most important critical arguments.

112. Kahneman et al., supra note 46 , at 1342 .

113. Sunstein, supra note 80 , at 130 (suggesting that hard wiring is one among several possible explanations of the endowment effect). 
Many authors have cautioned against using behavior observed in the laboratory to predict how people act outside of the laboratory. ${ }^{114}$ One concern is that the world outside of the laboratory is simply more complex, and the causes of behavior more diverse, than laboratory experiments capture. Subjects in the laboratory are not provided, for example, the long-term discipline of the marketplace or given a full opportunity to learn from their mistakes. We will have much more to say in Part III.B about the use and abuse of data from the laboratory by legal scholars.

Other authors have argued that behavioral economics as a whole, and endowment theory in particular, fail to provide an adequate or useful theory of the phenomena they describe. ${ }^{115}$ There are three salient versions of this no-theory critique.

Richard Posner has articulated a structural version, directed at behavioral law and economics writ large. In a 1988 response to Jolls, Sunstein, and Thaler's important and influential article, Posner argues that cognitive psychology has failed to provide a general model of human cognition that could replace rationalchoice theory.

The rational-choice economist asks what "rational man" would do in a given situation, and usually the answer is pretty clear and it can be compared with actual behavior to see whether the prediction is confirmed. Sometimes it is not confirmed — and so we have behavioral economics. But it is profoundly unclear what "behavioral man" would do in any given situation. $\mathrm{He}$ is a compound of rational and nonrational capacities and impulses. He might do anything. [Jolls, Sunstein, and Thaler] have neither a causal account of behavioral man nor a model of his decisional structure. ${ }^{116}$

114. Jennifer Arlen, Comment: The Future of Behavioral Economic Analysis of Law, 51 VAND. L. REV. 1765, 1769 (1998); Arlen et al., supra note 74, at 33-34; Samuel Issacharoff, Can There Be a Behavioral Law and Economics?, 51 VAND. L. REV. 1729, 1742 (1998); Jolls et al., supra note 62, at 1500; Donald C. Langevoort, Behavioral Theories of Judgment and Decision Making in Legal Scholarship: A Literature Review, 51 VAND. L. REV. 1499, 1522 (1998); Richard A. Posner, Rational Choice, Behavioral Economics, and the Law, 50 STAN. L. REV. 1551, 1566, 1570 (1998). Kelman describes the way rational choice theorists tend to deploy this argument. See Mark Kelman, Law and Behavioral Science: Conceptual Overviews, 97 NW. U. L. REV. 1347, 1377-78 (2003).

115. For other general criticisms of behavioral economics, see KELMAN, supra note 4 passim.

116. Posner, supra note 114, at 1559 (footnote omitted); see also Arlen, supra note 114, at 1768 (“[E]ven when people are not rational, behavioral analysis of law cannot necessarily provide an alternative framework for developing normative policy prescriptions because it does not yet have a coherent, robust, tractable model of human behavior which can serve as a basis for such recommendations."); Posner, supra note 114, at 1558 ("[Jolls, Sunstein and Thaler] don't establish a logical or other relation among the three assumptions that define behavioral economics."). 
Behavioral economics does no more than collect phenomena that might turn out to be wholly unrelated to one another, "just as the set of things that are not edible by man include stones, toadstools, thunderclaps, and the Pythagorean theorem." 117 Without a theory of cognition in general, behavioral economics cannot predict when the various phenomena observed in the laboratory will occur in the world.

The structural version of the no-theory critique is today outdated. Even in its early days, behavioral economics had an organizing principle. It collected phenomena that belied the predictions of the neoclassical model of human decisionmaking. Posner has recently recognized the value of that data and reasons for skepticism of the neoclassical model. ${ }^{118}$ In any case, in the twenty-five years since Posner wrote the above, behavioral economists have made significant progress in the development of predictive models. ${ }^{119}$ Posner's criticism no longer describes the field.

Another version of the no-theory critique is more specific to endowment theory. Some of the earliest contingent-valuation surveys and laboratory experiments produced evidence that the magnitude of observed WTA-WTP gaps and exchange asymmetries varies greatly and that in some contexts the phenomena do not appear at all. ${ }^{120}$ Many legal scholars have observed that if policymakers are to take account of endowment effects, they need a theory that predicts when to expect WTA-WTP gaps and exchange asymmetries, the probable magnitude of those phenomena, and how different legal rules are likely to affect them. ${ }^{121}$ Endowment theory, though it locates WTA-WTP gaps and exchange asymmetries within the broader phenomenon of loss aversion, is insufficient for that task. Prospect theory says only that potential changes in position experienced as losses are weighed more heavily than those experienced as gains. It does not say when a change is experienced as a loss or as a gain-what sets the reference point. Endowment theory suggests that owning something sets the reference point. But that answer is not fine grained enough to explain the data or predict when

117. Posner, supra note 114, at 1560.

118. GARY S. BECKER \& RiCHARD A. POSNER, UNCOMMON SENSE: ECONOMIC INSIGHTS, FROM MARRIAGE TO TERRORISM (2009).

119. See, e.g., Nicholas C. Barberis, Thirty Years of Prospect Theory in Economics: A Review and Assessment (Nov. 2012) (unpublished manuscript), available at http://papers.ssrn.com/sol3/ papers.cfm?abstract_id $=2177288$.

120. See, e.g., Hoffman \& Spitzer, supra note 38, at 109-11; Korobkin, supra note 60, at 1235-42. Part II.A discusses the early evidence in greater detail.

121. Extended discussions of this point can be found in Arlen, supra note 114, and Issacharoff, supra note 114. See also Arlen et al., supra note 74, at 7-8; Hoffman \& Spitzer, supra note 38, at 89, 111; Jones \& Brosnan, supra note 72, at 1949; Mark Kelman, Behavioral Economics as Part of a Rhetorical Duet: A Response to Jolls, Sunstein, and Thaler, 50 STAN. L. REV. 1577, 1588-89 n.32 (1998). 
the effect will appear. As Arlen, Spitzer, and Talley observe, "simply concluding that a person 'endowed' with a good exhibits loss aversion adds little to our understanding of which circumstances induce a person to 'endow' a good in the first instance." 122

A final version of the no-theory objection emphasizes not endowment theory's predictive powers, but its normative upshot. As Russell Korobkin puts the point, "the normative implications of the effect depend on its cause in particular circumstances." 123 To oversimplify a bit, the question is whether asymmetries in willingness to trade are caused by biases or by preferences. If cognitive biases and imperfect heuristics cause WTA-WTP gaps and exchange asymmetries, the lesson for preference-based lawmaking might be to take revealed valuations less seriously, to put less faith in markets, or to develop legal rules that correct for those biases or heuristics. If, on the contrary, WTA-WTP gaps and exchange asymmetries reflect people's considered preferences, the normative upshot is more difficult to sort out. Such endogeneity of preferences unsettles the ground that is meant to support preference-based policymaking and suggests the need for alternative welfare measures.

In addition to the no-theory critiques, many sophisticated treatments recognize that endowment theory is only one of several possible explanations of the observed phenomena. In one of the earliest systematic treatments in the legal literature, Elizabeth Hoffman and Matthew Spitzer identify six possible explanations of WTA-WTP gaps: ${ }^{124}$ (1) wealth effects, especially for nonsubstitutable goods; ${ }^{125}$ (2) prospect theory and the endowment effect; (3) the psychological need to close transactions; ${ }^{126}$ (4) reversion to buy-high/sell-low heuristics in the face of value uncertainty; ${ }^{127}$ (5) an aversion to regret for bad decisions that is given more weight in deliberations than the satisfaction that comes from a good de-

122. Arlen et al., supra note 74, at 9; see also Owen D. Jones, Time-Shifted Rationality and the Law of Law's Leverage: Behavioral Economics Meets Behavioral Biology, 95 NW. U. L. REV. 1141, 1160 (2001); Jones \& Brosnan, supra note 72, at 1951-52; Rachlinski \& Jourden, supra note 82, at 1557.

123. Korobkin, supra note 60, at 1256; see also Issacharoff, supra note 114, at 1736; Jolls \& Sunstein, supra note 91, at 222; Sunstein, supra note 80, at 131; Korobkin, supra note 38, at 689.

124. Hoffman \& Spitzer, supra note 38, at 85-98; see also Korobkin, supra note 60, at 1242-55; Sunstein, supra note 80, at 130-31; Korobkin, supra note 38, at 689-97.

125. See W. Michael Hanemann, Willingness to Pay and Willingness to Accept: How Much Can They Differ?, 81 AM. ECON. REV. 635 (1991); Levy \& Friedman, supra note 37 (applying Hanemann's theory to the legal context).

126. See Kelman, Consumption Theory, supra note 14, at 691-93.

127. See Richard C. Bishop et al., Contingent Valuation of Environmental Assets: Comparisons With a Simulated Market, 23 NAT. RESOURCES J. 619 (1983); Ronald A. Heiner, The Origin of Predictable Behavior, 73 AM. ECON. REV. 560 (1983). 
cision; ${ }^{128}$ and (6) framing effects caused by faulty experimental design. In formulating this point, it is important to distinguish two claims: that endowment theory is one bypothesis among others and that the theory identifies one cause among others. We are sympathetic to the former, but it can easily be confused with the latter. Endowment theory is a hypothesis about the causes of observed WTAWTP gaps and exchange asymmetries. The next Part describes new empirical evidence that the hypothesis is unable to explain the variation in results reported in the experimental literature. If this is correct, then endowment theory fails to identify a cause of observed WTA-WTP gaps and exchange asymmetries.

\section{EMPIRICAL FINDINGS FROM THE PAST DECADE}

All the cautionary voices we described in the previous Part accept that price and exchange experiments show what the experimenters say they show: that bare ownership can cause WTA-WTP gaps and exchange asymmetries. They accept that the laboratory experiments demonstrate that granting an entitlement to a good (a mug, a candy bar, a pen, and so on) will, all things being equal, affect subjects' expressed preferences with respect to that good. Leading legal scholars have characterized the "endowment effect" as one of the most robust empirical results of behavioral law and economics. Hovenkamp described "the offer-ask disparity" as "surprisingly tenacious, surviving repeated tests of many varieties and defeating every explanation offered to trivialize them or minimize the consequences." 129 Isacharoff wrote that "[ $t]$ he endowment effect is the most significant empirical observation from behavioral economics. It is of sufficient magnitude to merit serious consideration for attempting to predict behavior across a variety of settings." ${ }^{130}$ And Korobkin concluded that "[t]he endowment effect is undoubtedly the most significant single finding from behavioral economics for legal analysis to date," and "[i]n virtually every field of law, the endowment effect findings can be valuable to reexamining policy arguments explicitly or implicitly based on the status irrelevance assumption." 131

In the years immediately following the publication of the articles by Kahneman, Knetsch, Thaler, and Tversky, this seemed right. The psychology

128. Korobkin, Inertia and Preference, supra note 78, at 1610-26; Korobkin, The Status Quo Bias, supra note 78, at 657-61; Graham Loomes \& Robert Sugden, Disappointment and Dynamic Consistency in Choice Under Uncertainty, 53 REV. ECON. STUD. 271 (1986); Graham Loomes \& Robert Sugden, Regret Theory: An Alternative Theory of Rational Choice Under Uncertainty, 92 ECON. J. 805 (1982).

129. Hovenkamp, supra note 61 , at 55.

130. Issacharoff, supra note 114 , at 1735 .

131. Korobkin, supra note 60, at 1229, 1230. 
and economics journals were awash in articles employing similar methods that appeared to confirm endowment theory. ${ }^{132}$ Subsequent empirical data, however, have cast doubt on endowment theory as the best explanation for WTA-WTP gaps and exchange asymmetries observed in the laboratory. This Part provides a detailed description and discussion of two early experiments conducted by Charles Plott and Kathryn Zeiler, one of the authors of this Article. The first set of experiments focused on the valuation elicitation device used in the price studies that produced WTA-WTP gaps, the second on endowment methods and elicitation procedures employed in the trading experiments that produced exchange asymmetries. Our discussion of the Plott-Zeiler experiments and the surrounding literature is fairly technical because we think it is important for legal scholars to understand the empirical support for endowment theory. The currently available empirical data strongly suggest that explanations other than endowment theory account for WTA-WTP gaps and exchange asymmetries observed in the laboratory. This Part concludes with a discussion of subsequent empirical studies and the leading contemporary theories of WTA-WTP gaps and exchange asymmetries in the economics literature.

\section{A. The Strength of the Original Evidence}

Despite claims to the contrary, the early literature on WTA-WTP gaps reveals not only a lack of robustness but also support for explanations other than endowment theory for the gaps observed in the laboratory. A number of literature reviews demonstrated the lack of WTA-WTP gaps in a substantial number of contexts in which endowment theory would predict them and described alternative theories that might account for observed gaps. In a 1999 article, Thomas Brown and Robin Gregory summarized reported WTA-WTP ratios (the price at which subjects appear willing to part with something over the price they appear willing to pay to obtain it), which varied but were almost always greater than one. ${ }^{133}$ Although the result itself seemed robust, Brown and Gregory identified a wide variety of possible explanations for gaps. These included economic factors, such as income effects and substitution, transaction costs, implied value of the good, profit motives, and alternative psychological factors, such as legitimacy,

132. See, e.g., John K. Horowitz \& Kenneth E. McConnell, A Review of WTAWTP Studies, $44 \mathrm{~J}$. ENVTL. ECON. \& MGMT. 426, 426 (2002) (reviewing the literature and observing that "[t]he pervasiveness of high WTA/WTP ratios and the wide variety of goods that have been used in the experiments have combined to sustain interest in WTA vs. WTP for roughly 30 years").

133. Thomas C. Brown \& Robin Gregory, Why the WTA-WTP Disparity Matters, 28 ECOLOGICAL ECON. 323, 325 (1999). 
ambiguity, and moral responsibility. ${ }^{134}$ In 2002, John Horowitz and Kenneth McConnell produced a quantitative analysis of the impacts of experiment design features on the existence and magnitude of the gap. ${ }^{135}$ Although they claimed that the gap seemed robust, they noted that the body of research left open the question of whether "the WTA/WTP disparity provide[s] sufficiently broad and deep evidence against the neoclassical model."136 In a 2005 article, Serdar Sayman and Ayşe Öncüler also explored the impacts of design features on the presence and magnitude of the gap, finding variation in both. ${ }^{137}$ They hypothesized that the context in which valuations are elicited might affect reported valuations in two ways. First, the context might "affect the degree of strategic misrepresentation of the valuation." 138 Second, the context itself might "construct" valuations. ${ }^{139}$ Finally, Plott and Zeiler's 2005 review of the literature revealed variation in the presence of gaps correlated with design features used to control misconceptions about the elicitation device and to control other alternative explanations for observed gaps. ${ }^{140}$ These reviews alone provided important evidence against general claims of robustness and against endowment theory as the explanation for observed gaps.

\section{B. The Plott-Zeiler Experiments}

The predictive power of endowment theory lies in its claim that ownership alone is enough to affect willingness to trade. That claim relies on the laboratory evidence of WTA-WTP gaps and exchange asymmetries. Only in the laboratory is it possible to isolate the effects of ownership from other confounding causes. And the laboratory makes it easier to elicit binding choices, which provides an alternative to relying on reports of what a subject would do in a hypothetical situation.

In the early 2000s, Charles Plott and Kathryn Zeiler set out to test alternative explanations for the laboratory results. ${ }^{141}$ Their alternative hypotheses all

134. Id. at 26-29.

135. Horowitz \& McConnell, supra note 132.

136. Id. at 442 .

137. Serdar Sayman \& Ayşe Öncüler, Effects of Study Design Characteristics on the WTA-WTP Disparity: A Meta Analytical Framework, 26 J. ECON. PSYCHOL. 289 (2005).

138. Id. at 292.

139. Id.

140. Plott \& Zeiler, Willingness to Pay, supra note 3, at 533.

141. Some have suggested that Plott and Zeiler interpreted their results to imply that gaps and exchange asymmetries do not actually exist. See, e.g., Korobkin, supra note 7, at 10. Plott and Zeiler explicitly state the opposite. See Plott \& Zeiler, Willingness to Pay, supra note 3, at 542 ("The issue explored 
turned on the details of endowment methods and choice elicitation procedures. Plott and Zeiler first examined the design of previous price experiments, which ask subjects to attach a dollar value to goods. Then in a subsequent series of tests they examined the designs of earlier exchange experiments, which offered subjects the opportunity to exchange an endowed good for an alternative good. In order to understand Plott and Zeiler's discoveries, it will be necessary to go fairly deep into the mechanics of each type of experiment. The payoff will be a more complete understanding of both the original evidence for endowment theory and alternative theories that better explain the entire body of evidence, old and new.

\section{Evidence of Subject Misconceptions in Price Experiments}

Over the years, experimenters have devised a number of methods to test the robustness of WTA-WTP gaps in price experiments, which ask subjects to attach a monetary value to a good. The controls were designed to test alternative explanations for observed gaps. First, to rule out the possibility that reported valuations are not the product of strategic behavior or other confounding causes, experimenters must ensure that revealed monetary valuations reflect the subject's true valuation of the good. ${ }^{142}$ Experimenters use two tools to control for such alternative explanations: (1) an incentive-compatible mechanism designed to remove any incentive to misreport valuations and (2) anonymity, which precludes signaling and other alternative uses of valuation reports. Second, because incentive-compatible mechanisms are often complex and unfamiliar, further controls are needed to ensure that subjects' valuations are not systematically tainted by confusion or reliance on simple heuristics in the face of uncertainty. The three most common controls are training, unpaid practice rounds, and paid practice rounds.

In everyday exchange transactions, participants typically have good reasons not to reveal their true valuations. Most obviously, a seller who overstates his valuation will be more likely to receive a higher price, and a buyer who understates hers will be more likely to pay less than she otherwise would. Incentive-compatible mechanisms are designed to eliminate those strategic considerations. ${ }^{143}$ An example commonly used is the Becker-DeGroot-

here is not whether a WTP-WTA gap can be observed.... Instead, our interest lies in the interpretation of observed gaps.").

142. "True valuation" refers to an individual's valuation uninfluenced by strategic considerations introduced by a valuation elicitation mechanism or other mechanism that determines eventual allocation. ANDREW SCHOTTER, MiCROECONOMICS: A MODERN APPROACH 239 (2009).

143. See, e.g., David S. Brookshire \& Don L. Coursey, Measuring the Value of a Public Good: An Empirical Comparison of Elicitation Procedures, 77 AM. ECON. REV. 554 (1987) (finding that the gap's 
Marshak mechanism, which was developed in the early 1960s. ${ }^{144}$ For buyers, the mechanism works as follows: After bidding is complete, each bid is compared to a randomly generated number. If a bid is higher than or equal to the random number, the bidder buys the good and pays an amount equal to the random number. If a bid is lower than the random number, the bidder does not buy the good and keeps her money. In such an auction, a bidder maximizes her profits by bidding her true value for the good-the amount that makes her indifferent between the money and the good. If she bids higher than her true value, and the random number falls between her true value and her bid, she must buy the good for more than her true value. If she bids lower, and the random number falls between her true value and her bid, she passes up the chance to purchase the good for less than her true value. A similar structure is used to persuade sellers to reveal their true valuations.

Although in ideal conditions sophisticated auction designs such as the Becker-DeGroot-Marschak mechanism control for strategic behavior and other external influences, researchers have expressed concern that subjects might be unfamiliar with the market context or incentive-compatible mechanism used to elicit valuations. ${ }^{145}$ The worry is that subjects' uncertainty about how their reported valuations affect how much money they walk away with causes them to revert to their basic market instincts: sell high and buy low. ${ }^{146}$ Researchers have developed three types of techniques to address that concern: training, unpaid practice rounds, and paid practice rounds.

magnitude is significantly reduced when market mechanisms are used to elicit valuations); David S. Brookshire et al., Market Methods and the Assessment of Benefits: Some Further Results, in AMENITY RESOURCE VALUATION: INTEGRATING ECONOMICS WiTH OTHER DisCIPLINES 167, 168 (George L. Peterson et al. eds., 1988) ("Without the addition of a market-like elicitation procedure that induces truthful revelation of value, the gap and associated asymmetry between WTP and WTA measures should not be expected to disappear."); Don L. Coursey et al., The Disparity Between Willingness to Accept and Willingness to Pay Measures of Value, 102 Q.J. ECON. 679 (1987) (employing a Vickery auction to provide incentive for subjects to announce valuations devoid of external influences). But see Jack L. Knetsch et al., The Endowment Effect and Repeated Market Trials: Is the Vickrey Auction Demand Revealing?, 4 EXPERIMENTAL ECON. 257 (2001) (finding that in some contexts, Vickrey auctions are not incentive compatible).

144. Gordon M. Becker et al., Measuring Utility by a Single-Response Sequential Method, 9 BEHAV. SCI. 226 (1964). Another example is a Vickrey auction, in which the highest bidder wins but pays the amount bid by the second-highest bidder.

145. David S. Brookshire et al., Experiments in the Solicitation of Private and Public Values: An Overview, in 2 AdVANCES IN BEHAVIORAL ECONOMICS 173, 176 (Leonard Green \& John H. Kagel eds., 1990) ("If respondents treat the contingent valuations as an auction of a good that is not clearly understood ... and in a market context that is unfamiliar .... then a logical strategy is to adopt an initial bargaining position with extreme initial bids.").

146. Plott \& Zeiler, Willingness to Pay, supra note 3, at 538. 
Some experimenters provide training on the auction mechanism's operation. Some simply announce that it is in the subjects' best interests to report "true valuations." 147 Others explain to subjects the optimal strategy of revealing true valuations. ${ }^{148}$ Others provide subjects with a detailed explanation of the mechanism along with numerical examples of how reported valuations influence payouts. ${ }^{149}$ Some also test subjects for understanding of such explanations. ${ }^{150}$ While the procedures differ in approach, all have the same goal: to increase understanding of the elicitation device and therefore the likelihood that subjects report valuations independent of strategic considerations or misconceptions about how reported valuations map into payouts.

Yet other experimenters provide subjects an opportunity to practice using the elicitation mechanism and to ask questions. Practice is often provided in the form of unpaid rounds similar to the subsequent paid rounds used to measure valuation asymmetries. ${ }^{151}$ The purpose of practice rounds is to allow subjects to familiarize themselves with the elicitation mechanism so that noise due to error is minimized when experimenters elicit actual valuations to measure WTAWTP gaps.

147. See C. H. Coombs et al., Testing Expectation Theories of Decision Making Without Measuring Utility or Subjective Probability, 4 J. MATHEMATICAL PSYCHOL. 72 (1967); Kahneman et al., supra note 46; John A. List \& Jason F. Shogren, Price Information and Bidding Behavior in Repeated SecondPrice Auctions, 81 AM. J. AGRIC. ECON. 942 (1999); Loewenstein \& Issacharoff, supra note 73, at 160; Jason F. Shogren et al., Auction Mechanisms and the Measurement of WTP and WTA, 23 RESOURCE \& ENERGY ECON. 97 (2001).

148. See David W. Harless, More Laboratory Evidence on the Disparity Between Willingness to Pay and Compensation Demanded, 11 J. ECON. BEHAV. \& ORG. 359 (1989) (studying the effects of explaining the optimal strategy of the incentive-compatible mechanism to subjects); Knetsch, supra note 45 (providing detailed explanation to subjects and dismissing groups if 25 percent or more failed a quiz to test for understanding); Guido Ortona \& Francesco Scacciati, New Experiments on the Endowment Effect, 13 J. ECON. PSYCHOL. 277 (1992).

149. See Brookshire \& Coursey, supra note 143.

150. See Ian Bateman et al., A Test of the Theory of Reference-Dependent Preferences, 112 Q.J. ECON. 479, 494-95 (1997); Knetsch et al., supra note 143, at 266-67 (instructing "[i]t is in your best interest to indicate your true [WTA/WTP] in each trial," providing specific instructions on the market mechanism, and administering two questions to test for understanding).

151. See, e.g., Arlen et al., supra note 74 (providing two practice rounds with a test for understanding); Rebecca R. Boyce et al., An Experimental Examination of Intrinsic Values as a Source of the WTAWTP Disparity, 82 AM. ECON. REV. 1366, 1369 (1992) (providing ten unpaid practice rounds before one binding round); Coursey et al., supra note 143, at 684 (discussing the importance of providing practice rounds and providing four nonbinding trial rounds); Kahneman et al., supra note 46, at 1329-30 (providing hypothetical rounds for practice and to gauge understanding); Knetsch, supra note 45, at 1279 (providing one hypothetical round prior to actual measurements of valuations). 
Finally, some experimenters provide subjects with paid practice rounds to give subjects experience using the elicitation device. ${ }^{152}$ The idea here is that paid practice rounds more effectively promote learning so that by the time subjects participate in the round that produces data used to measure WTA-WTP gaps, they understand that announcing nonstrategic valuations will maximize their payouts.

Along a different dimension, some experimenters have argued that subjects who believe that their responses will be revealed to other subjects or to the experimenter might attempt to signal information about themselves. Fremling and Posner, for example, suggest that potential sellers might overstate the minimum amount of money they would be willing to accept in order to signal to others that their time is valuable. ${ }^{153}$ Or potential sellers who perceive a good as a gift from the experimenter might ask for more than they would otherwise as a way to signal gratitude for or appreciation of the "gift." One can imagine other signals participants might attempt to send, which could move revealed valuations either up or down. Controlling for signaling opportunities in the laboratory is relatively simple. Double-blind experiments ensure that neither the subjects nor the experimenter will learn the revealed valuations or individual subject payouts. ${ }^{154}$

152. See, e.g., Robert Franciosi et al., Experimental Tests of the Endowment Effect, 30 J. ECON. BEHAV. \& ORG. 213 (1996) (providing paid induced value token rounds to train subjects on the elicitation mechanism); Harless, supra note 148, at 376 (using binding second-price auctions); Knetsch \& Sinden, Willingness to Pay, supra note 42 (asking subjects to make binding decisions that resulted in possible cash compensation).

153. Gertrud M. Fremling \& Richard A. Posner, Market Signaling of Personal Characteristics (Univ. of Chi., John M. Olin Law \& Econ. Working Paper No. 87, 1999).

154. See, e.g., Arlen et al., supra note 74, at 12 ("All subjects were assigned a subject identification (ID) and were truthfully informed that all data were to be recorded only by subject ID number, thereby preserving anonymity."); Brookshire \& Coursey, supra note 143, at 560 (observing that subjects privately submitted bids in laboratory Smith auction rounds); Knetsch \& Sinden, Willingness to Pay, supra note 42, at 510 ("Discussions of chances and plans among participants were actively discouraged and the negotiations and money exchanges were done individually in an area away from other potential participants to minimize, or eliminate, informal influences and information flows to those waiting to declare their intentions."); Jason F. Shogren et al., Resolving Differences in Willingness to Pay and Willingness to Accept, 84 AM. ECON. REV. 255, 267 (1994) (noting in the instructions "[y]ou cannot reveal your bids to any other participant. Any communication between bidders during a trial will result in an automatic penalty of $\$ 3 "$ ). 
TABLE 1. Summary of Experiment Design Features That Control for Alternative Explanations When Measuring WTA-WTP Gaps

\begin{tabular}{|c|c|}
\hline Control & Purpose \\
\hline $\begin{array}{c}\text { Incentive-compatible } \\
\text { mechanism }\end{array}$ & To provide incentives for subjects to report true valuations \\
\hline Training & To increase understanding of elicitation device and optimal \\
strategy
\end{tabular}

In their 2005 study, Plott and Zeiler applied these five control mechanisms systematically to test whether gaps observed in the laboratory might not have been the product of subject misconceptions related to the elicitation device or signaling behavior. ${ }^{155}$ To do so, they conducted an experiment that implemented the union of controls collected from previous studies. ${ }^{156}$ First, valuations were elicited using the incentive-compatible Becker-DeGroot-Marschak mechanism to encourage subjects to announce their nonstrategic valuations. Second, in an attempt to control for misconceptions subjects might have about how the mechanism works, subjects were trained on how to determine the most they would pay as buyers and the least they would accept as sellers. Subjects also received training on exactly how the mechanism mapped reported valuations onto payoffs and were walked through examples illustrating why reporting nonstrategic valuations was the optimal strategy. Third, subjects participated in two nonbinding practice rounds using lotteries with cash outcomes, during which they were encouraged to ask questions. Fourth, before measurement of the gap, subjects participated in fourteen paid practice rounds using lotteries to develop a better understanding of the mechanism and to allow for learning from actual rewards and losses. Fifth, all decisions and payouts were made anonymously, which alle-

155. Plott \& Zeiler, Willingness to Pay, supra note 3.

156. Id. at 537-38. 
viated concerns that subjects might gravitate away from their true valuations to send a signal to other subjects or the experimenter.

The procedures were designed to test whether observed gaps support endowment theory or are attributable to alternative explanations such as subject misconceptions and signaling behavior. Endowment theory predicts that randomly assigned sellers will ask for more than randomly assigned buyers will bid. Therefore, the controls should have no effect on the results as long as they leave intact the subjects' positions as sellers or buyers. If, on the other hand, misconceptions or signaling drives observed gaps, controlling for those alternative explanations should eliminate the gap.

The results strongly support the conclusion that experimental procedures have driven observed WTA-WTP gaps in price studies. ${ }^{157}$ When the procedures employed by Kahneman, Knetsch, and Thaler were used, a statistically significant WTA-WTP gap is observed. The median WTA was $\$ 4.50$, whereas the median WTP was $\$ 1.50{ }^{158}$ When an incentive-compatible mechanism was employed, training on the mechanism was provided, subjects engaged in paid practice rounds, and decisions were anonymous, all in an effort to control misconceptions, no gap was observed. Using these procedures, no statistically significant difference is observed. The median WTA was $\$ 5.00$ and the median WTP was $\$ 5.00 .{ }^{159}$ To test for whether paid practice rounds are necessary to eliminate the gap, in one treatment subjects were trained and participated in two unpaid practice rounds, but not the fourteen paid practice rounds. Eliminating these rounds did not change the result: no gap was observed. ${ }^{160}$ Other researchers have replicated the Plott-Zeiler results using the same or similar procedures. ${ }^{161}$

157. See id. at 540

158. Id. at 536. Twenty-nine subjects reported valuations as sellers (WTA) and another twenty-nine as potential buyers (WTP). Mean WTA was $\$ 4.72$ (median=\$4.50; standard deviation=\$2.17) and mean WTP was $\$ 1.74$ (median $=\$ 1.50$; standard deviation=\$1.46). Id. A median test detected a statistically significant difference between medians (Pearson Xfire $=20 ; \mathrm{p}=0.00)$. Id.

159. Id. at 539-40. Mean WTA was $\$ 5.69$ (median $=\$ 5.00$; standard deviation= $\$ 3.83 ; \mathrm{n}=16$ ) and mean WTP was $\$ 5.20$ (median $=\$ 5.00$; standard deviation $=\$ 3.04 ; \mathrm{n}=15$ ). Id. A median test detected no statistically significant difference between medians (Pearson X2=0.04; $\mathrm{p}=0.84$ ). Id. The results proved robust to a change in the subject pool (community college students (experiment 3 ) versus law students (experiment 1$)$ ). Id.

160. Id. Mean WTA was $\$ 5.71$ (median $=\$ 5.10$; standard deviation $=\$ 4.00 ; \mathrm{n}=14$ ) and mean WTP was $\$ 7.88$ (median $=\$ 6.50$; standard deviation $=\$ 6.00)$. Id. A median test detected no statistically significant difference between medians (Pearson X2=0.15; p=0.69). Id.

161. See, e.g., Andrea Isoni et al., The Willingness to Pay-Willingness to Accept Gap, the "Endowment Effect," Subject Misconceptions, and Experimental Procedures for Eliciting Valuations: Comment, 101 AM. ECON. REV. 991 (2011); Stephanie Kovalchik et al., Aging and Decision Making: A Comparison Between Neurologically Healthy Elderly and Young Individuals, 58 J. ECON. BEHAV. \& ORG. 79 


\section{Evidence of the Influence of Enhancements in Exchange Experiments}

In a second set of experiments, Plott and Zeiler investigated whether observed asymmetries in simple exchange experiments are explained by endowment theory. ${ }^{162}$ In exchange experiments, subjects are given one good and asked whether they wish to trade it for a different one. Given the simplicity of the procedures, it is unlikely that observed asymmetries are the product of subject misconceptions. Plott and Zeiler therefore designed a collection of experiments to test a set of alternative theories. We will use the term "enhancement theory" to refer to the conjectures that arise from this set of alternative explanations.

Plott and Zeiler tested the alternative theories by altering four features of the conventional exchange experiment design. The first was the placement of the good at the time of choice. The conjecture was that placement might signal something to subjects about the relative value of the goods. Subjects could read value into the fact that the experimenter placed one good within reach while the other good was merely passed around from one subject to the next for inspection. To test for this possibility, subjects were required to choose with both goods immediately in front of them. ${ }^{163}$ In a more extreme treatment designed to test the impact of transaction costs, subjects made choices while the alternate good was immediately in front of them and the endowed good was placed at the front of the room. ${ }^{164}$

Plott and Zeiler also altered the experimenter's involvement in the choice of which good to give subjects. They hypothesized that subjects view items given them as gifts from the experimenter, which might prompt subjects to favor that item over another. Alternatively, or in addition, subjects might infer something about the relative value of the items from the experimenter's choice of which good to give them. To test for this, subjects were told that a random method was used to determine the distribution of goods.

Plott and Zeiler's third hypothesis was that collecting choices using raised hands might affect subjects' choices. It was observed in early pilots that some subjects appeared to use other subjects' choices as information about whether to trade. And some subjects later reported that they considered others' choices in

(2005); Weining Koh \& Wei-Kang Wong, The Endowment Effect and the Willingness to Accept-Willingness to Pay Gap: Subject Misconceptions or Reference Dependence? (2011) (unpublished manuscript), available at http://courses.nus.edu.sg/course/ecswong/research/WTAWTP.pdf.

162. Plott \& Zeiler, Exchange Asymmetries, supra note 3.

163. Id. at $1460-61$.

164. Id. at $1458-59$. 
reaching their own. By allowing subjects to view other subjects' choices, their attention might shift away from their own preferences to a determination of the possible right answer or to how others might perceive their choices. To control for these confounders, exchange decisions were gathered using forms rather than raised hands.

Fourth, Plott and Zeiler hypothesized that the experimenter's purposeful and repeated emphasis on ownership might influence choices. Because exchange experiments focus on the influence of entitlement on valuation, the experimenter must be confident that subjects understand that they own one of the goods. To do this, the experimenter might communicate this fact by repeating the message in a variety of ways (for example, "The mug is yours. I'm giving it to you. You own it."). While repetition can be an effective method for increasing the transfer of information, using this method in exchange experiments might inadvertently influence choices by signaling relative value. Subjects might infer too much from the experimenter's repeated message. To test for this, the procedures simply eliminated repetition of the message while at the same time taking steps to ensure that subjects understood they were entitled to the good they had been given.

TABLE2. Summary of Experiment Design Features That Control for Alternative Explanations When Measuring Exchange Asymmetries

\begin{tabular}{|c|c|}
\hline Control & Purpose \\
\hline Placement of good & $\begin{array}{c}\text { To eliminate potential signals of relative value } \\
\text { drawn from placement }\end{array}$ \\
\hline $\begin{array}{c}\text { Endowment randomly } \\
\text { determined }\end{array}$ & $\begin{array}{c}\text { To eliminate perception as gift and potential signals } \\
\text { of relative value }\end{array}$ \\
\hline Private choice & To eliminate choice dependence on others' choices \\
\hline $\begin{array}{c}\text { Elimination of repetition of } \\
\text { ownership status }\end{array}$ & $\begin{array}{c}\text { To eliminate potential signals of relative value or of } \\
\text { the significance of the act of endowment }\end{array}$ \\
\hline
\end{tabular}

By implementing these controls, Plott and Zeiler tested whether observed exchange asymmetries were caused by endowment theory or by enhancements generated by the procedures. Throughout these procedural manipulations one feature of the design remained constant: entitlement to one of the goods. Endowment theory would therefore predict a significant asymmetry in each treatment. If, on the contrary, observed asymmetries are attributable to proceduredriven enhancements, implementation of the controls should reduce or eliminate any exchange asymmetry. 
The results support the claim that observed exchange asymmetries are attributable to enhancements introduced by the procedures. To establish a baseline, previously published results were again replicated. Using standard procedures, 77 percent (34/44) of mug owners kept their mugs and only 62 percent $(32 / 52)$ of pen owners traded their pens for mugs, a statistically significant difference $(\mathrm{p}=0.06) .{ }^{165}$ When the standard procedures were altered to adopt all procedures thought to maximize enhancements, the exchange asymmetry increased. In this treatment, 84 percent (54/64) of mug owners kept their mugs but only 28 percent (18/65) of pen owners traded their pens for mugs, a highly statistically significant difference $(\mathrm{p}=0.00) .{ }^{166}$ When the full set of controls designed to eliminate enhancements were used, with entitlement remaining, the exchange asymmetry disappeared: 54 percent (37/69) of mug owners kept their mugs while 67 percent (47/70) of pen owners traded their pens for mugs. Owning a mug did not make one more likely to walk away with a mug $(\mathrm{p}=0.94) .{ }^{167}$ To further test whether the lack of possession of the endowed good at the time of choice drove the no-asymmetry result, both goods were placed in front of the subjects at the time of choice (the loss-emphasis test). No statistically significant asymmetry was observed $(\mathrm{p}=0.18)$. Again others have replicated or slightly modified the Plott-Zeiler procedures and obtained similar results. ${ }^{168}$

\section{Possible Misinterpretations}

The Plott-Zeiler experiments strongly suggest that there are better explanations than endowment theory for observed WTA-WTP gaps and exchange asymmetries. ${ }^{169}$ Before moving to subsequent studies and the reception of the

165. Id. at 1458. Note that all tests are one-tailed tests (i.e., the alternative hypothesis is 77 percent is 166. Id. greater than 62 percent).

167. Id.

168. See, e.g., Jack L. Knetsch \& Wei-Kang Wong, The Endowment Effect and the Reference State: Evidence and Manipulations, 71 J. ECON. BEHAV. \& ORG. 407, 408 (2009); Anmol Ratan, Mistakes, Closure and Endowment Effect in Laboratory Experiments 6 (Monash Univ. Dep't of Econ., Discussion Paper No. 22/12, 2012), available at http://www.buseco.monash.edu.au/eco/research/ papers/2012/2212mistakesclosureratan.pdf; Ori Heffetz \& John A. List, Is the Endowment Effect an Expectations Effect? 1, 4-7 (June 7, 2012) (unpublished manuscript), available at http://forum. johnson.comell.edu/faculty/heffetz/papers/assign-expect-endow.pdf.

169. To be clear, the Plott-Zeiler results do not reject prospect theory, but only its application to explain WTA-WTP gaps and exchange asymmetries. Prospect theory has garnered much support and has been refined in light of a broad empirical literature. Barberis, supra note 119, at 2-3. 
new data in the experimental literature, we address two possible misinterpretations.

Misinterpretation \#1: Although some experiments produce no gap, the weight of the evidence still supports endowment theory.

The argument here is that many more studies report gaps and the sheer number of studies finding a gap suggests that the recent studies might be missing something. ${ }^{.70}$

The Plott and Zeiler experiments demonstrate why piling up studies on each side of the scale is the wrong way to evaluate endowment theory's evidentiary support. The Plott-Zeiler studies identify numerous alternative explanations that find influence through a variety of experiment design features. Experiments showing gaps and exchange asymmetries that include those features are as much evidence for the Plott-Zeiler hypothesis as they are for endowment theory. If an experiment does not include proper controls, we cannot rule out alternative explanations for gaps and asymmetries.

Focusing on alternative explanations related to procedures allows us to divide studies into two categories: those that implement adequate sets of controls to eliminate alternative explanations and those that do not. Viewed from this perspective, claims that the weight of the evidence supports endowment theory are simply misguided. The fact that the number of studies that report gaps exceeds the number of studies that do not simply reflects the fact that in a large majority of studies, the design fails to implement proper controls to rule out alternative theories. The evidence suggests that gaps and asymmetries observed in these studies are driven not by reference dependence and loss aversion but by the alternative explanations. Given Plott and Zeiler's procedure-based alternative explanations, counting studies is unhelpful in evaluating the strength of the evidence for endowment theory. ${ }^{171}$

Misinterpretation \#2: The new data suggest that the existence and magnitude of gaps are context dependent.

170. We find suggestions of this response in Korobkin, supra note 60, at 1242-43 ("Although experimental conditions probably have some explanatory power [for observed gaps] in some cases, the weight of the evidence suggests that it is extremely unlikely that the effect is merely an artifact of the experimental methods that demonstrate it.").

171. Jennifer Arlen and Eric Talley have claimed that "[w]hile some studies finding the endowment effect admittedly fail to control for various important factors (e.g., incentive compatibility, strategic bargaining, wealth effects, anonymity effects, confusion, etc.), even after their exclusion there are a number of well-crafted studies that do offer such controls." Jennifer Arlen \& Eric Talley, Introduction to EXPERIMENTAL LAW AND ECONOMICS (Jennifer H. Arlen \& Eric L. Talley eds., 2008). Arlen and Talley provide no citations to such studies, and we are aware of none. 
A second misreading holds that the laboratory evidence taken as a whole demonstrates that the endowment effect is context dependent. ${ }^{172}$ This claim can be interpreted in two ways, depending on whether "endowment effect" refers to observed gaps and asymmetries (the phenomena to be explained) or to endowment theory as an explanation for them (the proposed explanation).

First, the response might be that the Plott-Zeiler data should cause us to expect gaps of different sizes or no gap depending on the context in which decisions are made. Although this is an important observation, it misses the connection between observations and explanations. The fact that gaps of varying sizes are observed in some contexts and not observed at all in others is of limited interest if we cannot draw relevant causal inferences from the data. Christine Jolls has argued that "in light of the central relevance of the endowment effect to normative economic analysis of law, it is appropriate to emphasize the important role of context in whether this effect occurs." ${ }^{" 73}$ This is fine as far as it goes. But to date we do not have a good general theory of the role of context. The purpose of altering contexts in laboratory experiments is to test alternative explanations for observed phenomena. Policymakers should not be interested in what features can turn gaps on and off in the laboratory. What policymakers should care about is what might cause gaps outside of the laboratory. The Plott-Zeiler experiments suggest the mere fact of ownership is probably not enough.

A second version of this response argues that the new results suggest that in some contexts our utility functions are kinked at ownership-based reference points, as described by endowment theory, and in other contexts they are not. On this reading, the new data suggest directing our efforts toward determining which contextual factors are associated with these preference characteristics. These associations will then allow us to develop a more nuanced endowment theory, which will allow us to predict more effectively contexts in which we will observe ownership-based gaps and asymmetries.

This interpretation again attempts to draw conclusions from observed gaps and asymmetries without considering the best explanation of those phenomena. The purpose of laboratory experiments is to generate data to test theories that can then be used to explain and predict behavior outside of the laboratory. Moving directly from laboratory data to applications outside of the laboratory,

172. Jolls \& Sunstein, supra note 91, at 205. ("[R]ecent evidence points to the influence of contextspecific features of the environment on the occurrence of the endowment effect. (Plott and Zeiler 2005)."); Christine Jolls, Behavioral Law and Economics 8, 9 (Yale Law Sch. Pub. Law \& Legal Theory Research Paper No. 130, 2006), available at http://ssrn.com/abstract=959177 ("The work by Plott and Zeiler (2005) provides an important recent lens on the role of context in determining the existence and degree of the endowment effect.").

173. Jolls, supra note 172 , at 8. 
without considering whether the data support one or another theory, misses a crucial step. ${ }^{174}$

Recall that endowment theory explains WTA-WTP gaps and exchange asymmetries as manifestations of loss aversion. What would a contextualized version of endowment theory look like? Most obviously, it would involve modifying the theory to predict gaps and asymmetries only in certain types of contexts. To ensure the theory is falsifiable, the theory must identify conditions that are sufficient to produce those gaps or asymmetries. And because theories are not just random collections of predictions, it must also posit plausible connections between those contextual conditions and endowment theory's explanation of observed disparities - namely, the fixing of reference points and loss aversion. Such a revised theory would posit that when we value goods in certain contexts, our expressed preferences are characterized by reference dependence and loss aversion, as assumed by endowment theory, whereas in other contexts, our expressed preferences satisfy the assumptions of expected utility theory or some other theory that does not include reference dependence and loss aversion.

It is difficult to see how the factors identified in the Plott-Zeiler studies could serve as empirical support for such a theory. Consider, for example, evidence that experimenter involvement in assigning endowments influences the presence of exchange asymmetries. A context-dependent endowment theory would explain that phenomenon by arguing that experimenter involvement either influences the reference point or increases subjects' sensitivity to loss aversion. Both claims are difficult to square with endowment theory. According to that theory, it is the endowment itself that sets the reference point, not the history of the endowment's acquisition. Adding that history as an explanation does not so much supplement the theory as supplant it with one or more alternative explanations. Nor is it obvious how endowment theory would explain why loss aversion should be stronger or weaker depending on the history of acquisition.

A more plausible explanation is that exchange asymmetries are caused not by the endowment simpliciter but by the way in which a good is acquired. Perhaps experimenter involvement changes the perceived nature of the good. Subjects compare not a mug and a pen, but a mug given them by an authority figure with whom they might have future dealings and a pen whose choice might offend that authority. Such a conjecture is a simpler and more plausible explanation of observed asymmetries than the hypothesis that experimenter in-

174. We develop these arguments in more detail in Part III. See also Kathryn Zeiler, Cautions of the Use of Economics Experiments in Law, 166 J. INSTITUTIONAL \& THEORETICAL ECON. 178 (2010). 
volvement somehow influences subjects' reference points or their behavior under loss aversion.

Or consider the observation that public choices influence the presence of exchange asymmetries. The Plott-Zeiler data suggests that asymmetries are more common when choices are made publicly. Expanding endowment theory to take account of context would mean positing some relationship between publicity of choice and the setting of reference points or the strength of loss aversion. This would require a story about why, for example, loss aversion is triggered or is more acute when subjects make public choices. Again, there is no obvious connection in the framework of the theory between these phenomena. The more plausible and parsimonious hypothesis is that the subjects' lack of raised hands trigger signal cascades about the "right choice" 175 and that this is what causes or magnifies exchange asymmetries when choices are public.

In short, although endowment theory might be modified to include context dependence, such a modification is not supported by the data that cast doubt on the simpler version of the theory. The contexts in which gaps and exchange asymmetries appear in the Plott-Zeiler experiments suggest explanations of the gaps and exchange asymmetries that have to do with familiar phenomena like subject misunderstanding, the misapplication of heuristics, deference to authority or earlier decisionmakers - explanations in which attitudes toward losses play no explanatory role.

Even if we abandon endowment theory, the Plott-Zeiler data do not indicate when we should expect WTA-WTP gaps or exchange asymmetries outside of the laboratory. The experiments suggest that alternative explanations related to laboratory procedures designed to elicit valuations and preferences drive observed gaps and asymmetries. But such procedures are found only in the laboratory. We need not worry, for example, that persons participating in everyday markets will misconceive how their actions translate into payoffs, as when we ask them to bid in a Becker-DeGroot-Marshak auction. In deciding whether to buy an item in a store, we simply compare the price to the amount we are willing to pay. When putting on price tags at a stoop sale, we think about what others might be willing to pay and what amount would compel us to give it up.

In fact, it is unclear whether we learn anything new from the Plott-Zeiler experiments-except that endowment theory is not the best explanation of WTA-WTP gaps and exchange asymmetries. We have long known that factors

175. If other experiment design features compel subjects to keep their endowed goods, few subjects will raise their hands to signal that they wish to trade. The initial lack of raised hands might compel others to keep their hands down, which will reinforce choices to keep the endowed good. 
like how we acquire a good and reputation can influence our choices. People are reluctant to toss a gift into the trash when the giver is watching. They consult third-party reviews before buying expensive goods, and obtain information about recent sales before putting their homes on the market. These are all familiar facts. Using these data to construct new theories is both unnecessary and unhelpful.

\section{Economics Research After Plott and Zeiler}

Since the appearance of Plott and Zeiler's articles, many economists have abandoned endowment theory, though to date they have not settled on an alternative explanation of the phenomena. Others continue to defend endowment theory, either attempting to answer Plott and Zeiler or ignoring their results. This Part provides a critical overview of that literature. The debates are far from over, and so we offer fairly detailed critiques of some recent claims. Our review of the literature is not exhaustive but will provide legal scholars with a sense of the state of the empirical and theoretical today and where it is headed.

Several authors have challenged Plott and Zeiler's proposed explanations of observed WTA-WTP gaps and exchange asymmetries. Jack Knetsch and WeiKang Wong have run a set of experiments designed to test whether Plott and Zeiler's failure to observe exchange asymmetries resulted from "conditions that weaken[ed] the perception of reference states" rather than from enhancement effects. ${ }^{176}$ Knetsch and Wong hypothesize that some of the Plott-Zeiler procedures, such as removing possession of the endowed good before eliciting choices, might reduce the perception of ownership. ${ }^{177}$ They also suggest that those procedures might "have successfully decoupled subjects' expectations from their initial ownership status." ${ }^{178}$ Knetsch and Wong therefore attempt to design experiments that control for all procedural features that concerned Plott and Zeiler and at the same time strengthen the perception and expectations of ownership.

The problem is that the procedures that Knetsch and Wong use to strengthen the reference point and establish a feeling of ownership create the very enhancements that they claim to avoid. ${ }^{179}$ Endowment theory maintains

176. Knetsch \&Wong, supra note 168 , at 408.

177. Id.

178. Id. (quoting Botond Köszegi \& Matthew Rabin, A Model of Reference-Dependent Preferences, 121 Q.J. ECON. 1133, 1142 (2006)) (internal quotation marks omitted).

179. A 2011 working paper by Weining Koh and Wei-Kang Wong on price experiments suffers from similar problems. Koh \&Wong, supra note 161. 
that the mere fact of ownership is enough to alter people's expressed preferences. Knetsch and Wong's attempt to strengthen the perception of ownership, however, reinstates the experimenter's involvement in the initial assignment of goods, has subjects earn the endowed good rather than simply receive it, and places the endowed good in front of subjects but not the alternative good. ${ }^{180}$ These procedures enrich the experience of acquiring the goods, rendering it difficult to separate endowment theory from enhancement theory as an explanation for observed asymmetries.

Andrea Isoni, Graham Loomes, and Robert Sugden have raised a different challenge. ${ }^{181}$ They question Plott and Zeiler's misconceptions conjecture by examining unreported data from the Plott-Zeiler price experiments in the 2005 article. Those data reveal gaps in valuations reported during the practice rounds, in which subjects reported valuations for lotteries as sellers and buyers. Using slightly altered procedures, Isoni, Loomes, and Sugden reproduced those gaps. They conclude that the data suggest that Plott and Zeiler's "no-gap result does not hold for (monetary) lotteries but does hold for mugs" and that the misconceptions theory is therefore not supported by all the data. ${ }^{182}$

Plott and Zeiler responded by performing a detailed analysis of all the lottery data - both theirs and those of Isoni, Loomes, and Sugden. They found evidence that subjects' beliefs about lottery outcomes were influenced by whether they were asked to report WTP or WTA, and they argue that those beliefs might have affected reported valuations. ${ }^{183}$ It turns out that sellers often provided WTA values at or above the maximum lottery payout while buyers often provided WTP values at or below the minimum lottery payout. ${ }^{184}$ Sellers seem to have believed they were likely to be winners, and buyers seem to have believed they would turn out to be losers. Previous experimental research using lotteries has demonstrated difficulties subjects have understanding such random devices. If an experiment does not control for those misunderstandings, and if misunderstandings correlate with seller/buyer roles, the data cannot distinguish the effects of ownership from the effects of those misconceptions. The result raises an important question about the original Plott-Zeiler procedures. Because Plott and Zeiler used lottery rounds only for training on the elicitation device and not to

180. Knetsch \&Wong, supra note 168 , at 409.

181. Isoni et al., supra note 161.

182. Id. at $1005-06$.

183. Charles R. Plott \& Kathryn Zeiler, The Willingness to Pay-Willingness to Accept Gap, the "Endowment Effect," Subject Misconceptions, and Experimental Procedures for Eliciting Valuations: Reply, 101 AM. ECON. REV. 1012 (2011).

184. Id. at $1017-24$. 
estimate the gap, those procedures did not control for lottery misconceptions. ${ }^{185}$ Further research is needed to determine whether Plott and Zeiler's revealed theory methodology might be applied to lotteries to eliminate misconceptions about lottery outcomes and lottery WTA-WTP gaps. ${ }^{186}$

Jennifer Arlen and Eric Talley offer two reasons for resisting the PlottZeiler conclusion "that the endowment effect phenomenon [is] the result of poorly designed protocols rather than the operation of Prospect Theory."187 First, they point out that "even the earlier studies that found no endowment effect arguably suffered from similar defects in subject training and understanding." 188 But the Plott-Zeiler claim that observed gaps are often caused by the lack of controls for subject misconceptions does not imply that such controls are necessary to eliminate valuation gaps. Other forces are capable of reducing the gap. Several studies have found no gap when employing incentive compatible mechanisms without training. ${ }^{189}$ But as Harinder Singh, an author of one of the studies, points out, the "disparate results can be reconciled by noting that [the studies that elicited no gap] employed assets/lotteries with risky...values, whereas [studies eliciting a gap] either employed lotteries with uncertain values or commodities which did not have specific value limits assigned to them." 190 The studies finding no gap also used 1.1 as the WTP/WTA ratio cutoff, rather than 1.0, to allow for a "modest income effect,"191 a benchmark that further reduces the likelihood of observing a gap. Plott and Zeiler test their misconceptions conjecture by giving the gap its best chance at appearing-using, for example, mugs to measure the gap and adopting the usual 1.0 cutoff.

Arlen and Talley argue, second, that Plott and Zeiler "utilized much more exhaustive experimental protocols, which themselves may have muted the endowment effect by changing the context of the experiment. In particular the

185. Charles R. Plott \& Kathryn Zeiler, Web Appendix to Endowment Effect Theory, Subject Misconceptions and Enhancement Effect Theory: A Reply to Isoni, Loomes and Sugden 7 (June 23, 2010), available at http:/www.aeaweb.org/aer/data/april2011/20100063_app.pdf.

186. Some recent work on lotteries finds only weak evidence for reluctance to trade an endowed lottery for another with the same distribution of possible monetary outcomes. See Pavlo Blavatskyy \& Ganna Pogrebna, Endowment Effects? "Even" With Half a Million on the Table!, 68 THEORY \& DECISION 173, 187 (2009).

187. Arlen \& Talley, supra note 171 , at xliv.

188. Id.

189. See Harless, supra note 148; Harinder Singh, The Disparity Between Willingness to Pay and Compensation Demanded: Another Look at Laboratory Evidence, 35 ECON. LETTERS 263 (1991). Both can be found in Plott and Zeiler's 2005 literature review. Plott \& Zeiler, Willingness to Pay, supra note 3 , at 533 .

190. Singh, supra note 189 , at 266 .

191. Id. at 264. 
Plott and Zeiler protocol required subjects to repeat the experiment." ${ }^{\text {192 }}$ Arlen and Talley suggest that "learning can affect valuation" and that subject preferences might be characterized by loss aversion, which dissipates "as subjects gain greater experience with trading the good (and experiencing the loss)," during which "they may discover that the loss is less painful than anticipated, and eventually may not exhibit either loss aversion or an associated ... gap." 193 Although it is important to consider alternative explanations, this conjecture is problematic along a number of dimensions. First, Arlen and Talley fail to mention Plott and Zeiler's treatment 2, which reveals no gap despite the fact that subjects did not participate in the fourteen paid practice rounds. Arlen and Talley's conjecture is less plausible if it assumes that participating in two hypothetical practice rounds leads subjects to discover that losses are less painful than anticipated. Second, Plott and Zeiler's practice rounds used lotteries rather than mugs. It is unclear how giving up a lottery ticket impacts learning about how one values a mug. Perhaps Arlen and Talley mean that experiencing losses generally helps us discover that losses of any sort are not very painful. But if this were the case, we would expect little to no loss aversion in the field, where losses are regularly experienced. Third, a number of experiments included hypothetical practice rounds and observed a gap. ${ }^{194}$ In fact, unlike in Plott and Zeiler's study, some used the same good during practice rounds and rounds in which gaps were measured. ${ }^{195}$ Arlen and Talley's second conjecture might deserve further study, but it does not fit the existing data.

We find some other challenges to Plott and Zeiler's conclusions less thoughtful. In his recent bestseller, Thinking, Fast and Slow, Daniel Kahneman provides a long footnote discussing the "ongoing debate about the endowment effect." 196 On the Plott-Zeiler price experiments, Kahneman suggests that the design mistakenly "communicates to the participants a message of what the experimenters consider appropriate behavior." ${ }^{197}$ This is an odd claim. First, Kahneman worries about Plott and Zeiler's method for training subjects to identify their nonstrategic valuation. But if anything, the method tips the scales to-

192. Arlen and Talley, supra note 171 , at xliv.

193. Id.

194. See, e.g., Boyce et al., supra note 151, at 1369-71; Kahneman et al., supra note 46; Knetsch, supra note 45 , at $1279-81$.

195. See, e.g., Kahneman et al., supra note 46.

196. DANIEL KAHNEMAN, THINKING, FAST AND SlOW 471 n.298 (2011).

197. Id. Kahneman does not explain what he means by appropriate behavior. He might mean that the design encouraged sellers to bid low and buyers to bid high to eliminate the gap. Or Kahneman might be claiming that the design suggested a correct value for the mug, so that both buyers and sellers would bid that amount, eliminating the gap. As explained above, we think neither correctly describes the Plott and Zeiler procedures. 
ward producing gaps, not erasing them. Buyers are told to start at one cent and work their way up to an amount that makes them indifferent between the money and the good; sellers are told to start high and work their way down. ${ }^{198}$ Such procedures are likely to anchor buyers' valuations to low amounts and sellers' to high amounts. ${ }^{199}$ Second, the actual bids reported in the study reveal substantial variation in reported valuations for both buyers and sellers, belying any claim that subjects received a message about a perceived correct value. ${ }^{200}$

On the Plott-Zeiler exchange experiments, Kahneman argues that the experimental design "does not allow the owner of the good to have physical possession of it, which is crucial to the effect."201 But Plott and Zeiler's loss emphasis treatment finds no exchange asymmetry even when owners are in physical possession of the good at the time of choice. ${ }^{202}$ Moreover, as noted above, endowment theory says nothing about the effects of physical possession. It claims that reference points are set by ownership. Modifying a theory to account for new evidence is an important part of the evolution of science. But when an experiment disconfirms a widely held theory $\mathrm{A}$, it is no criticism to charge that it fails to disconfirm a new hypothesis $\mathrm{B} .{ }^{203}$

Many other scholars have taken the Plott and Zeiler results as evidence against endowment theory. ${ }^{204}$ Several have attempted to extend Plott and Zeiler's own theory of their data by further testing the misconception conjecture, by developing more formal theoretical accounts of it, or by exploring the impact

198. Plott \& Zeiler, Exchange Asymmetries, supra note 3.

199. See Amos Tversky \& Daniel Kahneman, Judgment Under Uncertainty: Heuristics and Biases, 185 SCIENCE 1124, 1128 (1974) (describing anchoring as a process in which "people make estimates by starting from an initial value that is adjusted to yield a final answer... [and that] adjustments are typically insufficient").

200. Plott \& Zeiler, Willingness to Pay, supra note 3, at 539 tbl.4. In a similar vein, Jack Knetsch dismisses Plott and Zeiler's results by arguing that their explanation "seems to have more to do with particulars of the test design and less to do with the absence of an endowment effect under conditions that more realistically reflect the usual circumstances of actual ... valuations.” Jack L. Knetsch, Biased Valuations, Damage Assessments, and Policy Choices: The Choice of Measure Matters, 63 ECOLOGICAL ECON. 684, 685 (2007). But this gets things exactly backward. The common laboratory methods of eliciting valuations represent anything but the usual circumstances. The methods employ baroque auction mechanisms designed to encourage subjects to report nonstrategic valuations, without providing subjects any explanation of or training in those mechanisms.

201. KAHNEMAN, supra note 196, at 471 n.298.

202. Plott \& Zeiler, Exchange Asymmetries, supra note 3, at 1461-62.

203. We might add that the effects of physical possession in the setting of reference points are empirically unclear. When a person parks her car and then walks away from it, is she more likely to sell it for less than the amount she would demand while sitting in the driver's seat? The answer is far from obvious.

204. We have not evaluated the methodological soundness of the studies we describe from this point forward in this Part. Our aim is merely to provide an overview of the literature. 
of other market features on reported WTA-WTP gaps and exchange asymmetries. Timothy Cason and Charles Plott, for example, have begun examining in more detail how the Becker-DeGroot-Marschak mechanism can trip subjects up. ${ }^{205}$ They develop the notion of "game form recognition" to more precisely identify both how subjects misperceive features of the mechanism and how those misperceptions impact subjects' decisions. Dirk Engelmann and Guillaume Hollard have considered more deeply the impact of market experience on valuations. ${ }^{206}$ David Kingsley and Thomas Brown have explored the role of preference uncertainty, finding support for the claim that a "reduction in preference uncertainty ... is sufficient to eliminate the disparity, and provide[s] support for a model of preference uncertainty allowing for preference learning." ${ }^{207}$ In a separate work, Kingsley and Brown have also studied the effects of prompting subjects for revisions of their reported valuations, a feature of the Plott-Zeiler 2005 study. ${ }^{208}$ They find that prompting has an impact on reported valuations, which opens a question about which valuation, the first or the revised, should be considered one's true valuation. And Amy Coren has taken a deeper look at whether subjects follow "bargaining scripts," such as sell high and buy low. ${ }^{209}$

Plott and Zeiler's results have suggested to others alternative theories of observed gaps and asymmetries. An early response was Botond Köszegi and Matthew Rabin's expectations-based reference point theory. ${ }^{210}$ Köszegi and Rabin's expectation theory, like endowment theory, works within the loss-aversion framework of prospect theory. But rather than claiming that reference points are set by endowments, Köszegi and Rabin suggest that they are set by people's

205. Timothy N. Cason \& Charles R. Plott, Misconceptions and Game Form Recognition of the BDM Method: Challenges to Theories of Revealed Preference and Framing (Cal. Inst. of Tech., Social Science Working Paper No. 1364, 2012), available at http://papers.ssrn.com/sol3/papers.cfm?abstract_ id $=2151661$.

206. Dirk Engelmann \& Guillaume Hollard, Reconsidering the Effect of Market Experience on the "Endowment Effect," 78 ECONOMETRICA 2005 (2010); see also Pete Lunn \& Mary Lunn, What Can I Get for It? A Theoretical and Empirical Re-analysis of the Endowment Effect 1 (Econ. \& Soc. Research Inst., Working Paper No. 385, 2011) ("[F]indings imply that buyers and sellers consider not only their own preferences, but also their perceptions of potential deals.").

207. David C. Kingsley \& Thomas C. Brown, The Role of Preference Uncertainty in the Willingness to Pay-Willingness to Accept Disparity: An Experimental Test (2012) (unpublished manuscript) (on file with authors).

208. David C. Kingsley \& Thomas C. Brown, Does Prompting for Revision Influence Subjects' Offers in Willingness to Accept-Willingness to Pay Lab Experiments?, 32 ECON. BULL. 2580 (2012).

209. Amy Elizabeth Coren, Bridging the WTA-WTP Gap: Ownership, Bargaining, and the Endowment Effect (Aug. 2007) (unpublished Ph.D dissertation, University of Texas at Austin) (on file with authors).

210. See Köszegi \& Rabin, supra note 178. 
short-term expectations with respect to those endowments. ${ }^{211}$ Experimental tests of this theory reveal mixed evidence. Keith Ericson and Andreas Fuster interpret their data as demonstrating that reference points are set at least in part by expectations. ${ }^{212}$ They find that sellers who are not certain whether they will be able to trade an endowed good provide higher valuations than do sellers with no such uncertainty. ${ }^{213}$ In contrast, Ori Heffetz and John List find no evidence to support expectation theory and offer explanations unrelated to the model to reconcile their results with those of Ericson and Fuster. ${ }^{214}$ In short, the empirical support for Köszegi and Rabin's expectation theory is mixed, indicating that further research is needed.

Other theorists have suggested more significant departures from endowment theory. Some have designed experiments to test the impact of other experimental procedures on psychological processes that may lead to gaps and asymmetries. ${ }^{215}$ Others have attempted to apply complex game theoretical models to reconcile divergent experimental results. ${ }^{216}$ Still others have suggested that the magnitude of WTA-WTP gaps and exchange asymmetries might be determined by uncertainty about future preferences. ${ }^{217}$ All these models await further empirical verification, including in some cases replication of the original results. None operates within the broader framework of prospect theory, much less the narrower endowment theory.

Not everyone working in the fields of experimental economics and psychology has taken account of Plott and Zeiler's results. ${ }^{218}$ And we find some incor-

211. See id. at 1134 ("[W]e propose that a person's reference point is the probabilistic beliefs she held in the recent past about outcomes.").

212. See Keith M. Marzilli Ericson \& Andreas Fuster, Expectations as Endowments: Evidence on Reference-Dependent Preferences From Exchange and Valuation Experiments, 126 Q.J. ECON. 1879 (2011); see also Alec Smith, Lagged Beliefs and Reference-Dependent Preferences (Sept. 5, 2012) (unpublished manuscript), available at http://www.hss.caltech.edu/ acs/papers/lbrdu.pdf; Charles Sprenger, An Endowment Effect for Risk: Experimental Tests of Stochastic Reference Points (Nov. 1, 2010) (unpublished manuscript), available at http://economics.stanford.edu/files/ Sprenger1_31.pdf.

213. See Ericson \& Fuster, supra note 212, at 1888.

214. See Heffetz \& List, supra note 168.

215. See Nikolaos Georgantzis \& Daniel Navarro-Martínez, Understanding the WTA-WTP Gap: Attitudes, Feelings, Uncertainty and Personality, 31 J. ECON. PSYCHOL. 895 (2010); Eric J. Johnson et al., Aspects of Endowment: A Query Theory of Value Construction, 33 J. EXPERIMENTAL PSYCHOL. 461, 461 (2007) ("Merely altering the order in which queries are posed can eliminate the endowment effect, and changing the order of queries can produce endowment-like effects without ownership.").

216. See Herbert Gintis, The Evolution of Private Property, 64 J. ECON. BEHAV. \& ORG. 1 (2007).

217. See Graham Loomes et al., Taste Uncertainty and Status Quo Effects in Consumer Choice, 39 J. RISK \& UNCERTAINTY 113 (2009).

218. See, e.g., Ivo Bischoff, Endowment Effect Theory, Prediction Bias and Publicly Provided Goods: An Experimental Study, 39 ENVTL. \& RESOURCE ECON. 283 (2008); Ivo Bischoff \& Jürgen Meckl, 
rectly describing Plott and Zeiler's experimental design or conclusions. ${ }^{219}$ The primary message from the recent economic literature, however, is that many economists have now abandoned endowment theory, and that the search is on for alternative explanations of observed WTA-WTP gaps and exchange asymmetries. $^{220}$

\section{IMPLICATIONS}

Endowment theory entered legal scholarship as part of a broader critique of the neoclassical economic analysis of law. As we described in Part I, the theory appeared to fit a preexisting set of arguments: Kelman's, and then Kennedy's and Sunstein's, arguments that the Coase theorem failed to account for the ways that legal entitlements affect people's preferences or willingness to trade. Endowment theory also arrived packaged with the new discipline of behavioral economics, which provided a broader critique of neoclassical economics. Economists had always allowed that real people often act irrationally. So long as departures from rationality were randomly distributed, however, economists could argue that their rational-actor models were descriptively relevant. Behavioral economics marshaled empirical evidence not only that people are irrational but that they are irrational in systematic and predictable ways.

The enormous influence of endowment theory on legal scholarship, we believe, resulted in part from its location at the confluence of these two streams.

Endowment Effect Theory, Public Goods and Welfare, 37 J. SocIO-ECON. 1768 (2008); Lyle Brenner et al., On the Psychology of Loss Aversion: Possession, Valence, and Reversals of the Endowment Effect, 34 J. CONSUMER RES. 369 (2007); Graham Loomes et al., Preference Reversals and Disparities Between Willingness to Pay and Willingness to Accept in Repeated Markets, 31 J. ECON. PSYCHOL. 374 (2010); William W. Maddux et al., For Whom Is Parting With Possessions More Painful? Cultural Differences in the Endowment Effect, 21 PSYCHOL. SCI. 1910 (2010); Erica Mina Okada, Uncertainty, Risk Aversion, and WTA vs. WTP, 29 MARKETING SCI. 75 (2010); see also RICHARD H. THALER \&

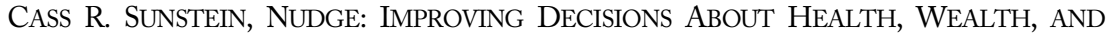
HAPPINESS 33-34 (2009) ("Thousands of mugs have been used in dozens of replications of [the Kahneman, Knetsch and Thaler experiments], but the results are always the same.").

219. See, e.g., Stefano DellaVigna, Psychology and Economics: Evidence From the Field, 47 J. ECON. LIT. 315, 327 (2009) (incorrectly stating that "Plott and Zeiler interpret [their] result as suggesting that, once one allows for experience and anonymity, the endowment effect disappears"); John A. List, Neoclassical Theory Versus Prospect Theory: Evidence From the Marketplace, 72 ECONOMETRICA 615, 616 n.4 (2004) (incorrectly stating that Plott and Zeiler's 2005 study demonstrates that "when adequate instruction about the allocation institution is provided, subjects' behavior is consistent with neoclassical predictions").

220. This conclusion is consistent with a new summary of the relevant economics literature, which interprets recent evidence as suggesting that, while loss aversion might remain a relevant component of the explanation for observed reluctance to trade, the evidence seems clear that reference points, if they are relevant at all, are set by more than mere ownership. See Ericson \& Fuster, supra note 212. 
The earlier critique of the Coase theorem described a constellation of considerations that, in many contexts, might increase an owner's attachment to the goods or other entitlements she owned. Endowment theory, consistent with the general approach of behavioral economics, suggested a single, omnipresent cause: loss aversion. Together, these arguments flipped the burden of persuasion. Whereas earlier critics had to explain why having one or another legal entitlement might effect a positive change in the holder's expressed preferences, the existence of a general endowment effect licensed the presumption that any legal entitlement would effect such a change.

As discussed in Part II.A, the evidence for endowment theory was never as strong as described by some early proponents. And as endowment theory gained influence within legal scholarship, it lost ground among experimentalists. The data we have today suggest that there are better explanations than endowment theory for observed exchange asymmetries and WTA-WTP gaps. Yet legal scholars continue to speak as if the theory were empirically unassailed. This disconnect between legal scholarship and the best theories in contemporary experimental economics suggests several questions: What does the new evidence mean for legal analysis? Why has endowment theory been so influential in legal scholarship? And what does legal scholarship's embrace of endowment theory teach us more generally about the use of experimental economics in law? This Part addresses each in turn.

\section{A. Against Endowment Theory: Ownership, Preferences, and Endogeneity}

The Plott-Zeiler experiments and other new data indicate that ownership alone is insufficient to cause WTA-WTP gaps and exchange asymmetries. Even if we assume arguendo that prospect theory is accurate, the evidence does not show that ownership sets the reference point and that individuals are especially averse to losses of endowments. Bare ownership is not enough to trigger loss aversion, or more generally, to affect expressed preferences with respect to entitlements. The Plott-Zeiler experiments indicate that in the laboratory those phenomena commonly result from experimental designs that fail to control for alternative explanations. If there are WTA-WTP gaps and exchange asymmetries outside the laboratory, they stand in need of other explanations.

What does all this mean for legal scholarship? To reject endowment theory is not to argue that preferences are exogenous to the law, or to argue that the allocation of legal entitlements does not affect what people want and value. Many arguments for and explanations of endogeneity antedate endowment theory and 
survive its demise. Those arguments, however, involve more complex stories about how a variety of factors related to ownership can affect preference formation in a variety of ways and for a variety of reasons. Sometimes ownership matters because the things people own are part of their personal history. Sometimes it matters because people know more about what they have than about what they do not and that knowledge is valuable. Sometimes wealth effects and nonsubstitutability make a difference. Sometimes people treat the law's assignment of an entitlement as presumptively authoritative. Sometimes there is a desire to withdraw from the marketplace, which entails a preference simply to keep what one already has. Sometimes regret aversion is at work. Sometimes cultural norms speak against selling. Sometimes the cause involves adaptive preference formation and a rational choice to prefer that which one has to that which one cannot have.

In short, the evidence against endowment theory casts doubt only on the generic presumption that ownership positively affects expressed preferences. To repeat: The data do not support the hypothesis that the bare fact of ownership (or endowment or entitlement) affects preferences or is the cause of observed WTA-WTP gaps and exchange asymmetries. Legal scholars who want to claim that one or another legal entitlement is likely to trigger such gaps or asymmetries should provide either empirical evidence or an alternative theoretical argument for their claim. In many cases, such evidence and arguments will no doubt be available. But merely pointing to the fact of ownership, or to the existence of a legal entitlement, is not enough.

\section{B. Why Endowment Theory's Influence?}

Why did endowment theory have such an immediate and enduring influence in legal scholarship? We have already suggested one hypothesis: the confusion caused by the term "endowment effect." Although experimental economists use "endowment effect" to denote a theoretical explanation of WTA-WTP gaps and exchange asymmetries, the term suggests an observed fact about the world. Here we want to suggest six other nontestable hypotheses. Each warrants longer treatment than we can give it. And they are almost certainly not the only explanations why the theory found such a receptive audience among legal scholars. But we think these explanations go a long way. The first two are historical and emphasize what else was happening in legal scholarship when endowment theory appeared. The other four involve more general observations about how legal scholarship works. 
Endowment theory was the right theory at the right time. By the early 1990s, neoclassical law and economics had become a major force in the legal academy. As early proponents of endowment theory recognized-Kahneman, Knetsch, and Thaler titled their 1990 article "Experimental Tests of the Endowment Effect and the Coase Theorem" - endowment theory undermined the foundations of neoclassical legal analysis. The genius of Coase was to see that laws create entitlements that their holders might then trade, either in practice or in theory. This thought paved the way for the application of the familiar tools of welfare economics to the law. Economists could study the welfare effects of different legal regimes by looking at whether, in the absence of transaction costs and wealth effects, the resulting entitlements would be traded. Such analysis assumes that the initial distribution of entitlements does not affect people's willingness to trade. In the legal literature, that assumption was recognized and criticized a decade before endowment theory appeared. Kelman argued in 1979 that legal entitlements are likely to affect people's preferences with respect to the endowed goods. But Kelman's, and then Kennedy's and the early Sunstein's, critiques of Coase rested in large part on anecdote and intuition. Endowment theory provided the familiar critique with new scientific credentials, credentials to which economists could not possibly object. Korobkin has recently written that "[1] egal scholars have universally grasped the most important positive implication of the endowment effect - that legal entitlements will not change hands as often in the free market as the Coase Theorem-and thus traditional law and economics-assumes." 221 This Article belies Korobkin's sweeping description of legal scholars. But the statement illustrates the attraction of endowment theory's perceived implications for neoclassical law and economics.

The theory also arrived as part of a larger attempted paradigm shift. Endowment theory appeared at a time when legal scholars were beginning to take account of a wide range of cognitive phenomena that ran contrary to the predictions of neoclassical economics. Many of the earliest and most influential legal scholars to take note of endowment theory did so in articles that put it on a long list of cognitive biases, heuristics, and nonstandard preferences. ${ }^{222}$ The endowment effect was presented as a phenomenon comparable to the hindsight bias, the optimism bias, the outcome bias, and the availability heuristic. Its appearance on such lists located endowment theory in the broader counternarrative of

221. Korobkin, supra note 7, at 2.

222. See, e.g., BEHAVIORAL LAW \& ECONOMICS (Cass R. Sunstein ed., 2000); Jolls et al., supra note 62; Jolls \& Sunstein, supra note 91; Russell B. Korobkin \& Thomas S. Ulen, Law and Behavioral Science: Removing the Rationality Assumption From Law and Economics, 88 CALIF. L. REV. 1051 (2000); Langevoort, supra note 114; Sunstein, supra note 64. 
behavioral law and economics. And it suggested that the endowment effect was a simple fact of human psychology, one that required no further explanation.

Other possible explanations for the success of the theory have to do with the character of legal scholarship more generally. To begin with, early laboratory experiments captured the legal imagination. ${ }^{223}$ The initial, random distribution of mugs and candy bars in Knetsch's 1989 exchange experiments embodied the core claim of the Coase theorem and mirrored familiar hypothetical bargains between ranchers and wheat growers, railroads and farmers, polluting factories and neighboring landowners. The difference was that in the laboratory it was possible to control the initial assignment of entitlements, to reduce transaction costs to near zero, and to observe the resulting exchanges. The Coase theorem, it turned out, was in fact a falsifiable hypothesis. Coase predicted that with transaction costs approaching zero, the initial assignment of mugs and candy bars would not make a difference in their final distribution. The experiments proved that hypothesis wrong. Especially for legal scholars trained in the art of argument by analogy, the implications were striking. Giving someone the legal entitlement to clean air, to the performance of a contract, to build on her land was like giving her a mug or a candy bar. Laboratory results involving the mugs and candy bars therefore showed that more abstract legal entitlements were also likely to affect willingness to trade. We say more about this tendency of legal scholars to misapply argument by analogy in the final section of this Part.

Nor should we ignore the influence of a few leading scholars in the field and the path dependency of legal scholarship. Most legal scholars are not trained in cognitive psychology or experimental economics, and many would not know where to begin in the experimental literature. So they rely on other scholars to educate them on the topic. As of 2011, Jolls, Sunstein and Thaler's 1998 "A Behavioral Approach to Law and Economics" was the most cited law journal article published since 1995..$^{224}$ Although 91 articles in Westlaw's Journals and Law Reviews database cite Kahneman, Knetsch, and Thaler's 1990 article in the Journal of Political Economy, ${ }^{225} 274$ articles in the database that mention "endowment effect" cite to Sunstein, Jolls, and Thaler. ${ }^{226}$ Of those 274 articles, 171 do not

223. Of the over 1200 articles in Westlaw's Journals and Law Reviews database that mention "endowment effect," see supra note 59 and accompanying text, 133 mention in the same paragraph the words "mug," "pen," "chocolate," or "candy." Search conducted on October 18, 2013.

224. Russell Korobkin, What Comes After Victory for Behavioral Law and Economics?, 2011 U. ILL. L. REV. 1653, 1654.

225. Search conducted on October 18, 2013, using Westlaw's JLR database and the search term "knetsch /s 'experimental tests of the endowment effect and the Coase theorem."

226. Search conducted on October 18, 2013, using Westlaw's KeyCite function and using the locate function to limit search results to articles with the term "endowment effect." 
cite any of the three foundational articles from the behavioral economics literature. ${ }^{227}$ This one slice of data does not, by itself, make the case. But we think it reflects a general truth about how work from other disciplines enters into and spreads through legal scholarship. Endowment theory has been championed as part of the next big thing by some of the most influential agenda setters and opinion leaders in legal scholarship. Without equally loud voices raising doubts or explaining more recent data, other scholars have stuck with endowment theory.

Yet another explanation lies in the commonalities between endowment theory and the neoclassical approach it criticized. Although endowment theory, and behavioral economics more generally, posed a challenge to neoclassical economics' model of the rational actor, it did not challenge a core methodological premise: that to understand and predict human action, we should begin with the preferences of individuals. Endowment theory explains endogeneity by pointing to the individual person's tendency to attach more significance to losses than to gains. As Mark Kelman observes, economists have been much more receptive to such psychological criticisms than to social theories of preference formation, "though the sociological attacks are arguably more salient in undermining the conventional position." 228 Kelman suggests three reasons why this is so: the psychological critique can be translated into the economists' language of preference and choice, it comports with economists' understanding of power as commands backed by the threat of force, and it treats the social world as nonindependent of the individuals who comprise it. ${ }^{229}$ Endowment theory treats exchange asymmetries and WTA-WTP gaps as bare expressed preferences, explained if at all by individuals' aversions to loss. All this is the stuff of neoclassical economic analysis. ${ }^{230}$

Finally, there is the political valence of endowment theory and of behavioral economics more generally. ${ }^{231}$ As Kelman observed in his 1979 article, no matter what Coase's intent, his theorem has an "ideological structure."232 The Chicago School used it to argue for the superiority of markets and the futility of regula-

227. Identical search to that described in the previous note, except also using the locate function to exclude articles with the strings "experimental tests of the endowment effect and the Coase theorem," "the endowment effect and the effect of nonreversible indifference curves," or "loss aversion in riskless choice."

228. Kelman, supra note 114 , at 1389.

229. Id. at $1388-92$.

230. To put the point more crudely, in the 1990s and early 2000s, it was possible to get Olin Foundation money for research to the endowment effect. We doubt that it would have been as easy to get Olin dollars to study the social origins of preferences. See TELES, supra note 8, at 181-207.

231. Thanks to Lama Abu-Odeh and John Mikhail for, in different ways, pushing us on this point.

232. Kelman, Consumption Theory, supra note 14, at 673-78. 
tion. And the idea of exogenous preferences, central to the Coase theorem, lies at the heart of the charge that the regulatory state is unduly paternalistic. Endowment theory provides a counterargument. Regulation is paternalistic only when it gives insufficient weight to people's independently formed preferences. If preferences themselves are partly produced by state action, interference is inescapable and the paternalism criticism loses its footing. ${ }^{233}$ Endowment theory's argument against Coase provides a seemingly objective and scientifically neutral basis for what might be an ideological critique. This would hardly be the first example of utilizing scientific theories to advance political ends. Think of Thomas Huxley's social Darwinism, B.F. Skinner's behaviorist psychology, or Lawrence Kohlberg's and Carol Gilligan's different works on the ethical development of children. Each has a political valence, and each was adopted by legal scholars for political as well as academic purposes. Behavioral economics in general, and endowment theory in particular, have been used by left-leaning academics as support for new forms of "soft" paternalism. ${ }^{234}$ We do not doubt the sincerity of any of these writers whose scholarship we have examined. But we would guess that the utility of endowment theory in this ideological debate is part of the explanation for its success in legal scholarship. ${ }^{235}$

\section{Experimental Economics and Legal Scholarship}

The story of endowment theory also contains broader methodological lessons about the use in legal scholarship and policymaking of experimental economics and cognitive psychology, and perhaps of results from other social sciences as well. ${ }^{236}$

The most obvious lesson borders on the trite: Be careful. Legal scholars should draw from the social sciences. When they do, however, they need to understand the materials they are using. First-year law students are taught not to cite a case without first Shepardizing it. Before citing a twenty-year-old study from experimental psychology, or any other discipline, legal scholars should look for any subsequent developments in the field. When using more recent studies, legal scholars should have a clear understanding both of their empirical support and of alternative theories.

233. See Cass R. Sunstein \& Richard H. Thaler, Libertarian Paternalism Is Not an Oxymoron, 70 U. CHI. L. REV. 1159 (2003). For criticisms of Thaler and Sunstein's "liberal paternalism" theory from the libertarian right, see Joshua D. Wright \& Douglas H. Ginsburg, Behavioral Law and Economics: Its Origins, Fatal Flaws, and Implications for Liberty, 106 Nw. U. L. REV. 1033 (2012).

234. For a bestselling recent example, see THALER \& SUNSTEIN, supra note 218.

235. For more on this subject, see KELMAN, supra note 4, at 13-15.

236. For a detailed discussion of these issues, see Zeiler, supra note 174. 
We recognize that it can be difficult for legal scholars to find their way into the literature of nonlegal disciplines. We would therefore welcome two innovations. First, we would like to see more law review articles that report recent developments in the social sciences. Such pieces would depart from the normal form of a law review article, which is to start with a legal question or problem, apply one or another analytic method, and conclude with a practical proposal. We are not against articles of that sort. This work follows the model. But there should also be room in the law reviews for articles that aim simply to educate legal scholars and policymakers about the most recent developments in other fields. Such scholarship would depart from the dominant model of law review articles, which are often briefs for a preferred theory. An evenhanded account of the state of the field, however, will be of most use to policymakers. ${ }^{237}$

Second, we would like to see more educational opportunities for legal scholars. The legal academy is today awash in minicourses on experimental and empirical methods. For five hundred or a thousand dollars, a law professor can spend a week learning the basics of experimental design and one or another statistical software package to crunch data. Rather than teaching legal scholars how to do social science - for example, how to perform laboratory experiments-we think it is more valuable to teach them important recent results from the social sciences. It is true that one cannot evaluate results from experimental psychology, sociology, neurobiology, or other science without a basic understanding of experimental methodology. Equally important, however, is an understanding of the competing theories in the field, their history, and how to access and keep abreast of the literature. These materials can be taught to legal scholars with great benefit. The recent appearance of short courses in brain science aimed at legal scholars might well provide a model. ${ }^{238}$

The story of endowment theory in the legal literature also contains a more general and somewhat subtler lesson. It illustrates the dangers of using results from the laboratory as a basis for formulating legal policy. As we noted in Part I.D, it is not unusual for legal scholars to caution against the use of laboratory re-

237. We have some concerns, for example, with Russell Korobkin's recent review of the endowment effect literature. Although Korobkin states that his review "describes the endowment effect, with attention not only to what we know about it, but also what remains unclear about both its scope and underlying causal mechanism," he discusses the Isoni, Loomes and Sugden's 2011 challenge without mentioning Plott and Zeiler's response to it. Korobkin, supra note 7, at 2; see supra notes 182-186 and accompanying text. As a result, Korobkin's readers are left in the dark about serious problems with Isoni, Loomes and Sugden's data and direct evidence against their alternative explanations.

238. See, e.g., Neuroscience Boot Camp, CENTER FOR NEUROSCIENCE \& SOC'Y, http://neuroethics. upenn.edu/index.php/events/neuroscience-bootcamp (last visited Sept. 24, 2013). 
sults in policymaking. The worry is almost always that the world outside of the laboratory is much more complex than the intentionally simplified world within it. Arlen puts the point as follows:

$[\mathrm{T}]$ he environment in which people actually operate and make choices is far more complex than the environment of most behavioral experiments. Although many (but by no means all) experiments involve single-shot situations, people in the real world often are able to learn from their experiences. This learning generally takes place in situations involving higher stakes than are involved in most experiments.... Further complicating matters, many decisions will implicate multiple biases and heuristics-involving multiple interrelated individualsthat may produce unpredictable, complex, or even conflicting interactions. ${ }^{239}$

Issacharoff emphasizes the role of emotions and institutional settings in decisions outside of the laboratory. ${ }^{240}$ Posner argues more generally that "[o]ne would like to know the theoretical or empirical basis for supposing that the experimental environment is relevantly similar to the real world." 241 Jolls, Sunstein, and Thaler argue more optimistically that "it is not enough to build a model consistent with behavior observed in an experimental setting (such as behavior in the ultimatum game or the mugs experiments); the model must be compared and tested against what we observe in the world." ${ }^{42}$ The world inside of the laboratory is just too different from the world outside of it to use laboratory results to predict what will happen in the outside world.

Although these cautions are not baseless, we think they miss the mark and draw attention away from the real problem with the way many legal scholars employ empirical studies. In order to explain why, we need to return to the distinction we drew in Part I between two types of laboratory experiments. Experimental economists typically conduct experiments that involve highly stylized situations designed to test a general hypothesis by isolating a single cause. We call these "simple experiments." To test the best explanation of WTA-WTP

239. Arlen, supra note 114, at 1769; see also Arlen et al., supra note 74, at 33-34.

240. See Issacharoff, supra note 114, at 1741-42. Langevoort makes a similar point:

The next level of question is the profound translation problem of moving from the assumption that cognitive biases are real to the assumption that they are robust in the institutional settings in which most of the economic activity that the law seeks to influence takes place.... Markets, social norms, and organizations all constrain individual decision making in such a way that we cannot be sure that biases found in artificial settings will be pernicious in real life.

Langevoort, supra note 114 , at 1522.

241. Posner, supra note 114 , at 1570.

242. Jolls et al., supra note 62 , at 1500. 
gaps or exchange asymmetries, subjects might be given low-value items like mugs or candy bars and then asked to assign a value to them or given the chance to exchange them for other items. The experiments are simple in the sense that they put subjects in stripped-down, nonhypothetical situations that are unlikely to occur outside of the laboratory and then observe how the subjects respond. A few legal scholars interested in WTA-WTP gaps and exchange asymmetries have conducted simple experiments of this sort. ${ }^{243}$ Other empirically oriented legal scholars have conducted experiments of a different type. They have asked subjects to answer hypothetical legal questions modeled on situations that might occur outside the laboratory. Subjects are asked to pretend that they are lawyers negotiating a contract term, that they are employees with the option of paying for or giving up an employment benefit, or that they are trustees for a land trust who have been asked what to do with a piece of wetlands. ${ }^{244}$ We call experiments of this sort "hypothetical" because they ask subjects to imagine themselves in a situation that might occur in the world outside of the laboratory and to engage in role-play or to report how they would decide. Subject choices have no consequences.

The common warnings about the use of laboratory results in policymaking are entirely correct as applied to hypothetical experiments. Hypothetical experiments attempt to replicate naturally occurring transactions or other legal situations in the laboratory in order to predict how people will behave outside of it. It is always relevant to ask of such experiments whether laboratory conditions are similar enough to conditions outside of the laboratory. Does it matter, for example, that subjects do not have a stake in the game? Does it matter that they are students and not practitioners? Does it matter that they have been asked to reach their decision in a relatively short amount of time? Although hypothetical experiments are increasingly common in the legal literature, few legal scholars (and even fewer student editors of law reviews!) have the training necessary to evaluate their methods or the implications of their results with respect to behavior outside the laboratory. When applying the results of such experiments, one should worry that decisions outside the laboratory might be subject to forces that the experimental design has failed to capture, that the outside world is more complex than the one created in the laboratory.

We think that the complexity worry is less apposite to the simple experiments commonly conducted by experimental economists, at least when those ex-

243. See supra notes $73-76$ and accompanying text.

244. See supra notes $77-83$ and accompanying text. 
periments are properly deployed. The problem is that the worry fails to get at what is actually wrong with the way legal scholars use these sorts of experiments.

Simple experiments are by definition designed not to reproduce similar events outside the laboratory but to provide empirical support for, or disconfirmation of, general theories of individual decisionmaking. They "are employed to explore fundamental economic principles and test predictions of basic economic models that incorporate these principles." ${ }^{245}$ If they predict behavior outside of the laboratory, it is only by way of the general theories they serve to confirm. Those general theories, in turn, are confirmed or disconfirmed not by one or two experiments but by multiple tests using different experimental designs of the many distinct hypotheses the theory generates.

The problem with the way legal scholars have used simple experimentssuch as the repeated invocation of Knetsch's 1989 mug and candy bar experiment-is not that the world that concerns policymakers is much more complex than the world in the laboratory. Nor is it, as Jolls, Sunstein, and Thaler suggest, that legal scholars fail to compare and test experimental models "against what we observe in the world." 246 The problem is that direct appeal to simple experiments to predict the behavior of legal actors misunderstands the purpose of those experiments and the meaning of the data they generate. It is as if legal scholars were using a screwdriver to scramble eggs. It is not wrong to advise someone who wants to scramble her eggs with a screwdriver to be sure to clean it first. No one wants to eat toolbox grime for breakfast. But that advice draws attention away from the more important point: Screwdrivers are not designed for scrambling eggs, and they are likely to do a poor job of it, no matter how carefully they are used. By the same token, a warning that "the environment in which people actually operate and make choices is far more complex than the environment of most behavioral experiments" ${ }^{247}$ draws attention away from the fact that the simple experiments are not designed to predict what people will do in the world outside of the laboratory. They are designed to confirm or disconfirm theories. It is those theories, not the simple experiments that support them, that are meant to tell us things about the world.

Legal scholars and policymakers should use the results of experimental economics. But they should pay much less attention to the results of individual apparently salient simple experiments. Nor should they attempt to design experiments for the purpose of drawing normative conclusions about behavior in

245. Zeiler, supra note 174 , at 182-83.

246. Jolls et al., supra note 62, at 1500.

247. Arlen, supra note 114, at 1769. 
legal contexts that are difficult or impossible to mimic in the laboratory. Instead, legal scholars and policy makers should look first and foremost to applicable theories that are best supported by empirical evidence writ large.

This objection to legal scholars' use of simple experiments rather than theories is very different from the no-theory objections canvassed in Part I.D. We are not arguing that experimental economics does not have the right structure, that endowment theory is not yet fine-grained enough to say when WTA-WTP gaps and exchange asymmetries will occur, or that it matters whether behavior is caused by biases or by specific features of preferences. No matter what you think of those points, ours is different. It is that legal scholars and policymakers should apply well-supported cognitive theories, not the results of simple experiments they think mimic legally relevant situations. As lawyers, we are trained in arguments from analogy and highly adept at finding similarities among different fact patterns. Those legal virtues are likely to lead us astray when thinking about the policy implications of simple experiments. We should instead attend to the more general theories that those experiments support. Theory provides a necessary bridge between the simple settings in experiments and more complex settings that concern policymakers.

\section{CONCLUSION}

This Article argues against endowment theory and is critical of the widespread appeals to an "endowment effect" in legal scholarship. We have not argued for a return to the neoclassical economic model of human decision making that endowment theorists have criticized. Nor do we intend this Article as an indictment of behavioral law and economics more generally. Legal scholars should use results from experimental economics, cognitive psychology, and related disciplines. In fact, our argument against endowment theory does just that. Endowment theory should be rejected because the recent data and current leading theories suggest that loss aversion coupled with ownership is not the best explanation for observed WTA-WTP gaps and exchange asymmetries. Legal scholars should draw from the social sciences. But they should do so as sophisticated consumers. 